\title{
$6926 E_{-73}$ MHSMP-69-
}

\section{AXO DETONATOR}

\author{
L. D. Hanes \\ June, July, August 1969 \\ Purchase Order Nos. $9316-75$ \& 9316-77 \\ An investigation of some' of the factors affecting performance of a coaxial type \\ spark gap detonator.

\section{ABSTRACT} \\ A factorial spark gap detonator study is presented, with the results. UK PETN, \\ (MF $81 / 10,6200 \mathrm{~cm}^{2} / \mathrm{g}$ ) at $1.12 \mathrm{~g} / \mathrm{cm}^{3}$ had a higher voltage breakdown and a higher \\ power deposition than others in the test. \\ A somewhat unusual firing system employed for these tests is described.
}




\section{DISCUSSION}

A factorial type experiment was performed on AX0 type detonators with 10-mil electrode spacing using preaged powders. The three-factor, three level experiment was performed for the purpose of determining the effect of specific surface areas (or particle sizes), density, and energy input (including rate of energy input) upon various dependent variables. The independent factors and the levels of each are outlined in Table 1.

The fire set used for the tests was a triggered spark gap type wi th a modified output, shown schematically in Fig. 1. The output circuit capacitor $C_{2}$, which electrically parallels the AXO detonator, is charged through the 15-ohm resistor by capacitor $C_{1}$ upon triggering the spark gap. By adjusting the value of $C_{2}$ one can control the slope of the voltage ramp as seen by the AxO detonator. This somewhat unorthodox fire set was chosen so that voltage profile could be monitored and power profile calculated.

The current contributed by capacitor $C_{1}$, the current contributed by capacitor $C_{2}$, di/dt of $C_{2}$ mixed with the AXO output pin pulse, and voltage across the AxO were recorded on Tektronix 519 oscilloscopes. A typical set of film records-PX PETN 8220 at $1.00 \mathrm{~g} / \mathrm{cm}^{3}$ fired with capacitor $C_{2}$ of $0.04 \mu \mathrm{f}$-is shown in Fig. 2. The currents were summed to obtain the total current through the AXO. Transmission time $\left(t_{e}\right)$ was measured from voltage breakdown to pinswitch ionization using records 3 and 4 ; the fiducial marked was used for time orientation between the two records. Voltage breakdown is defined as the breakover point between the semi-linear voltage ramp and the exponential decay (sum of two exponentials each due to one of the capacitors discharging through the AX0). 
Factors

Capacitance

Powder Type

Density
Level I

$.01 \mu f$

PX PETN 8227*

$0.88 \mathrm{~g} / \mathrm{cm}^{3}$
Level II

$.02 \mu f$

PX PETN $8220^{\dagger}$

$1.00 \mathrm{~g} / \mathrm{cm}^{3}$

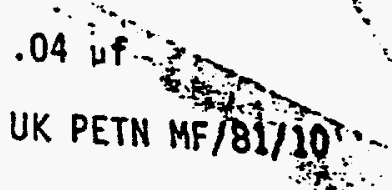

$1.12 \mathrm{~g} / \mathrm{cm}^{3}$

*Freaged $96 \mathrm{hrs}$. $100^{\circ} \mathrm{C}, S_{0}^{p}=3200 \mathrm{~cm}$ 9.5 , LRL Quarterly Report for July, August, September 1968

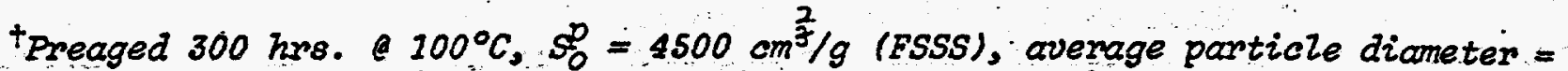
7.45 \%, LRL Quarterly Report for July, August, September 1968.

$+t_{\text {Preaged }} 300 \mathrm{hrs}$ e $100^{\circ} \mathrm{C}, S_{0}^{p}=6200 \mathrm{~cm} / \mathrm{2} / \mathrm{g}$ (FSSS), average particle diameter $=$ 5.5 u, Sandia Quarterly Report for September, October, November 1967. 


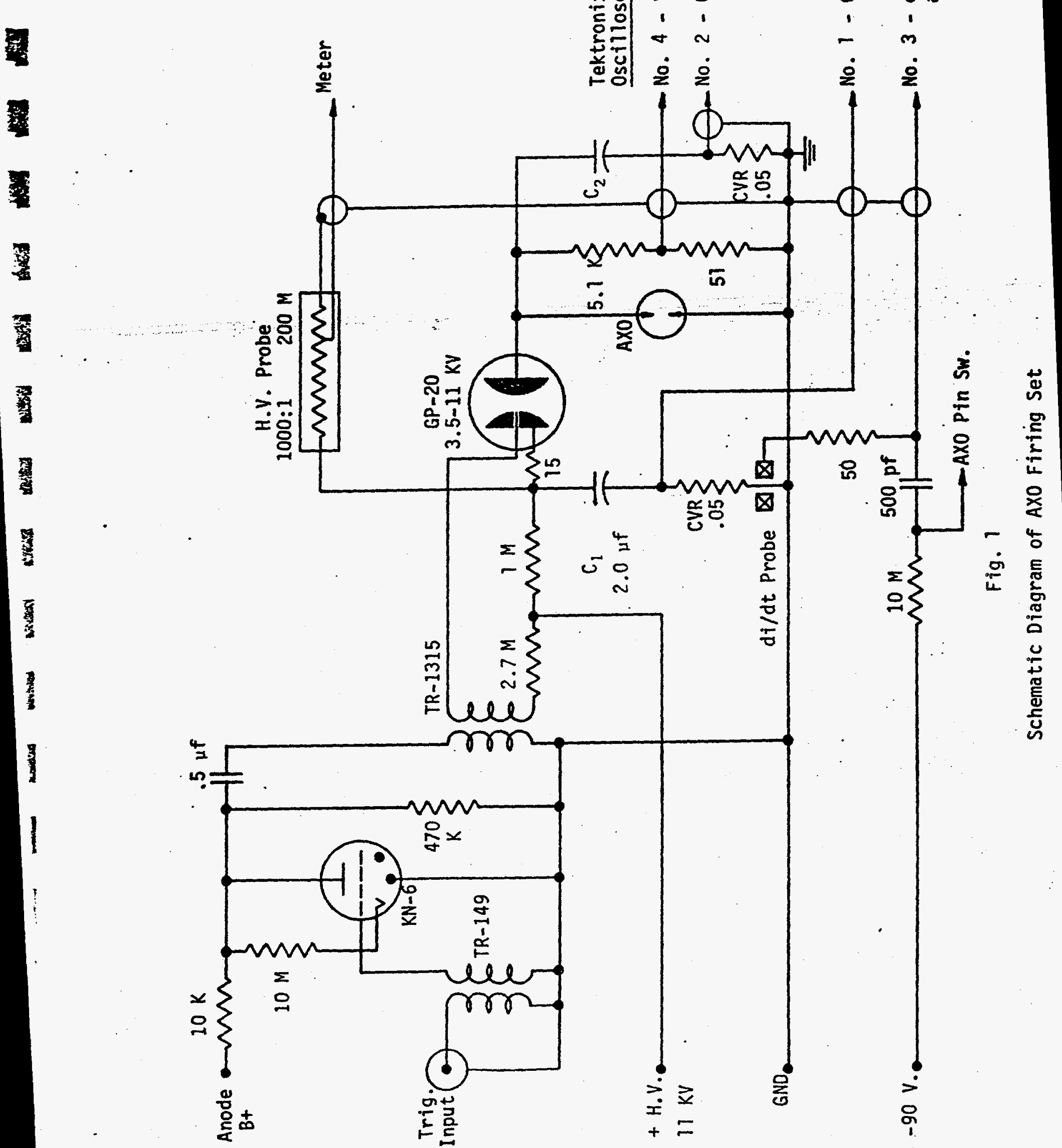


Fig. 2

AxO Test Records

(PK PETN Batch $8220,4500 \mathrm{~cm}^{2} / \mathrm{g}, 1.00 \mathrm{~g} / \mathrm{cm}^{3}$ )

$\left(C_{1}=2.0 \mu \mathrm{f} ; C_{2} \cdot=0.04 \mu \mathrm{f}\right)$

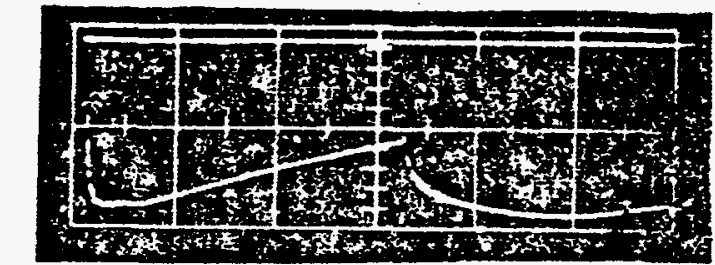

$200 \mathrm{~ns} / \mathrm{cm}$

$186 \mathrm{~A} / \mathrm{cm}$

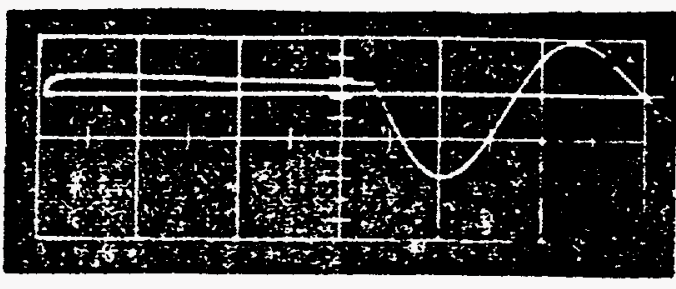

$200 \mathrm{~ns} / \mathrm{cm}$

Display of the current delivered by capacitor $C_{1}$ (left) and capacitor $C_{2}$ (right). The CVR's were connected for negative polarity.

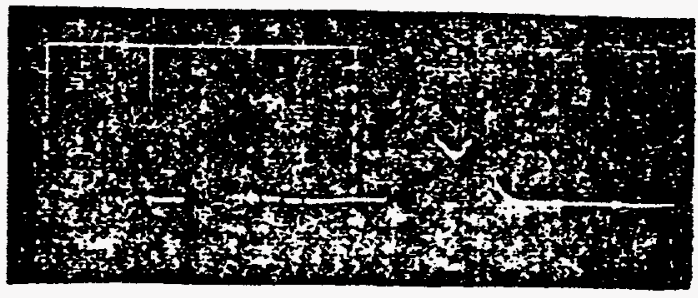

$500 \mathrm{~ns} / \mathrm{cm}$

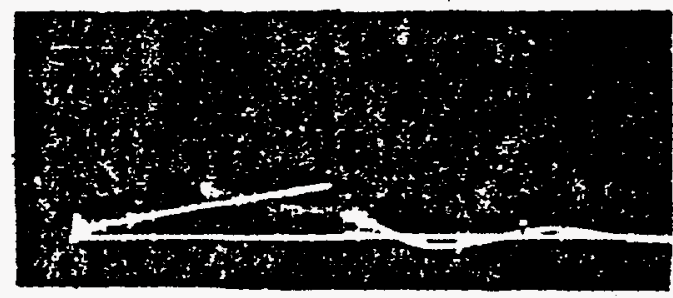

$200 \mathrm{~ns} / \mathrm{cm}$

$9.3 \mathrm{kv} / \mathrm{cm}$

Display of the di/dt and pin switch (left) and the voltage across the Axo (right).

櫂

要聚

都密 
Data reduction included the assessment of breakdown voltage, transmission time, peak current, time rate of change of the voltage ramp, time rate of change of the current following breakdown, power profile from voltage breakdown to the peak power point, and peak power.

Power expended in the AXO detonator versus time measured from breakdown is plotted in Figs. 3 through 11.

An analysis of variance was computed for six dependent variables-breakdown volgage, transmission time, peak current, peak power, di/dt following breakdown, and $d v / d t$ for the charging ramp. These results are given in Tables II through VII.

The relative importance of the independent variables can be estimated from the size of the mean square deviations listed in Tables II through VII: the greater the number, the higher the probability of significance. Actual significance cannot be presently computed because the experimental error is not determinable. (There was no replication because of cost and availability of hardware.) Main and first-order effects of the independent variables on breakdown voltage and transmission time are plotted in Figs. 12 through 27 with plus or minus one sigma bars which, it should be remembered, represent the effect of the factors that are averaged into each point. The other dependent variables and second-order effects are not plotted because they are apparently not significant. 


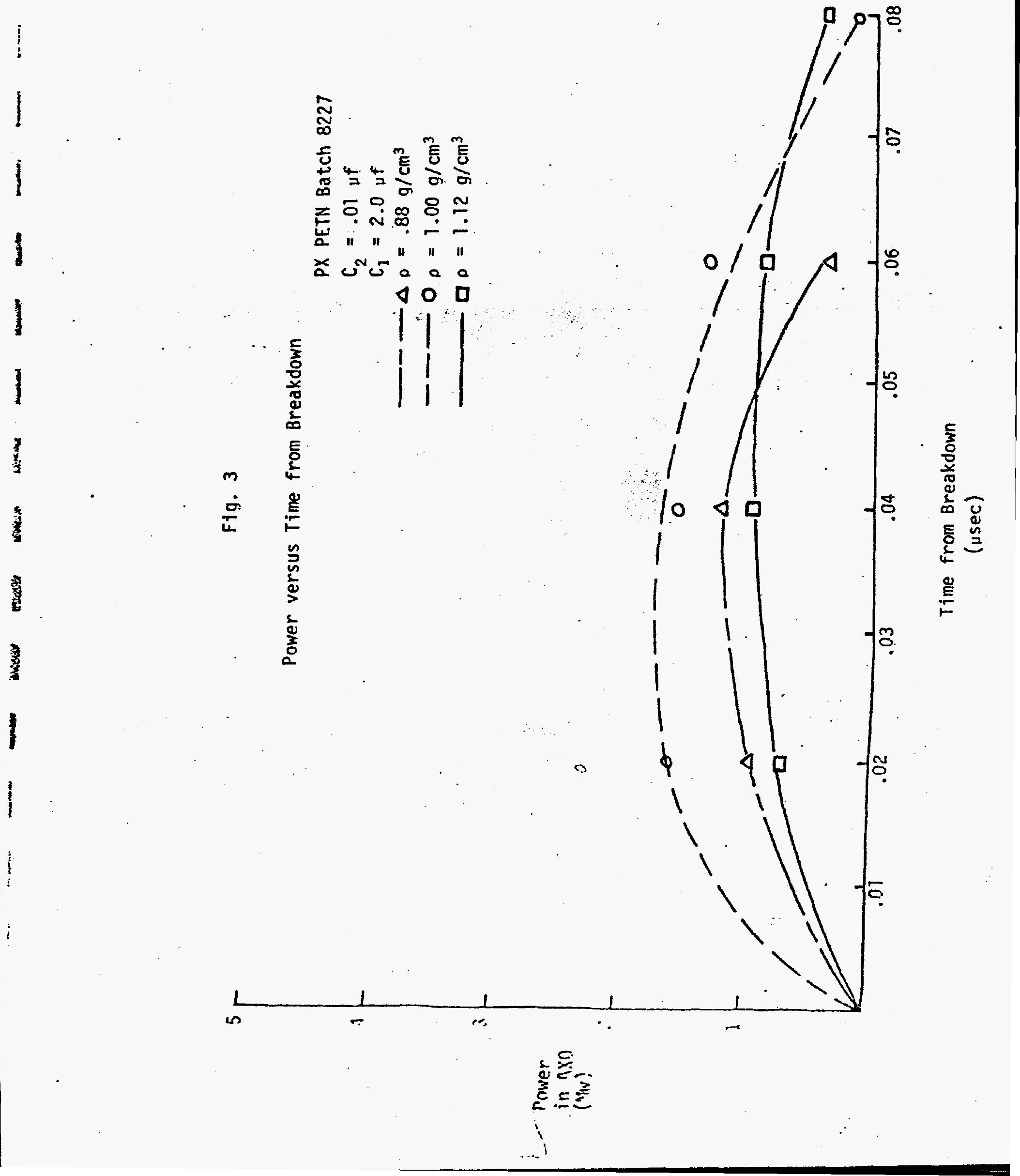




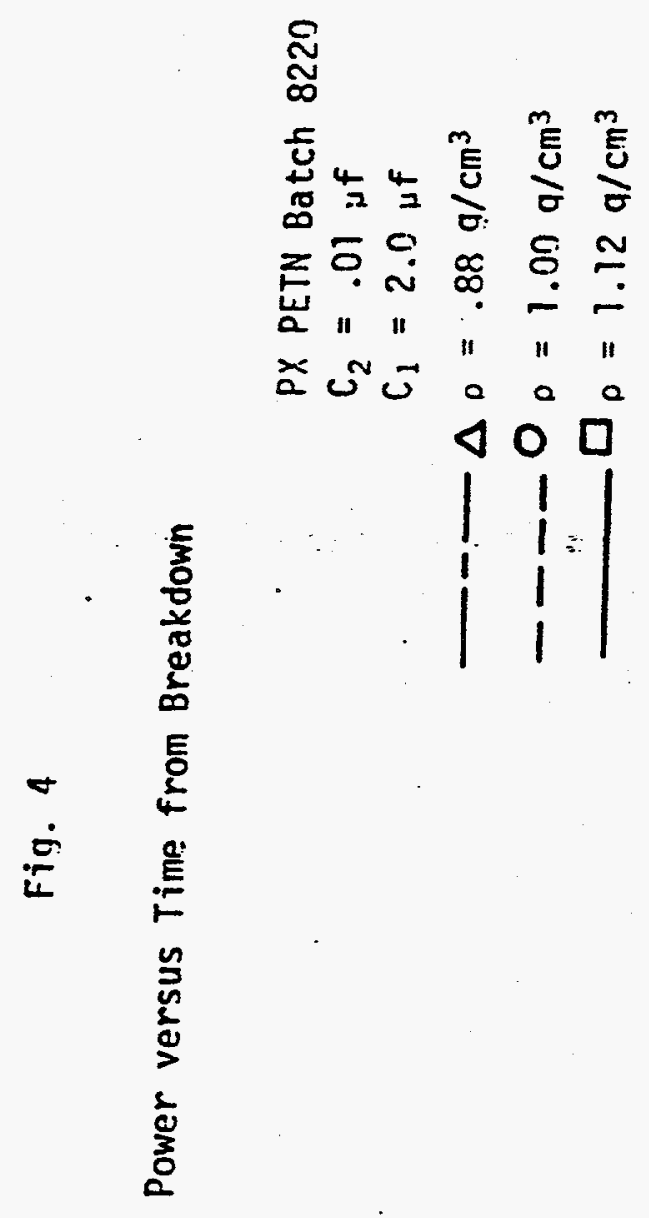




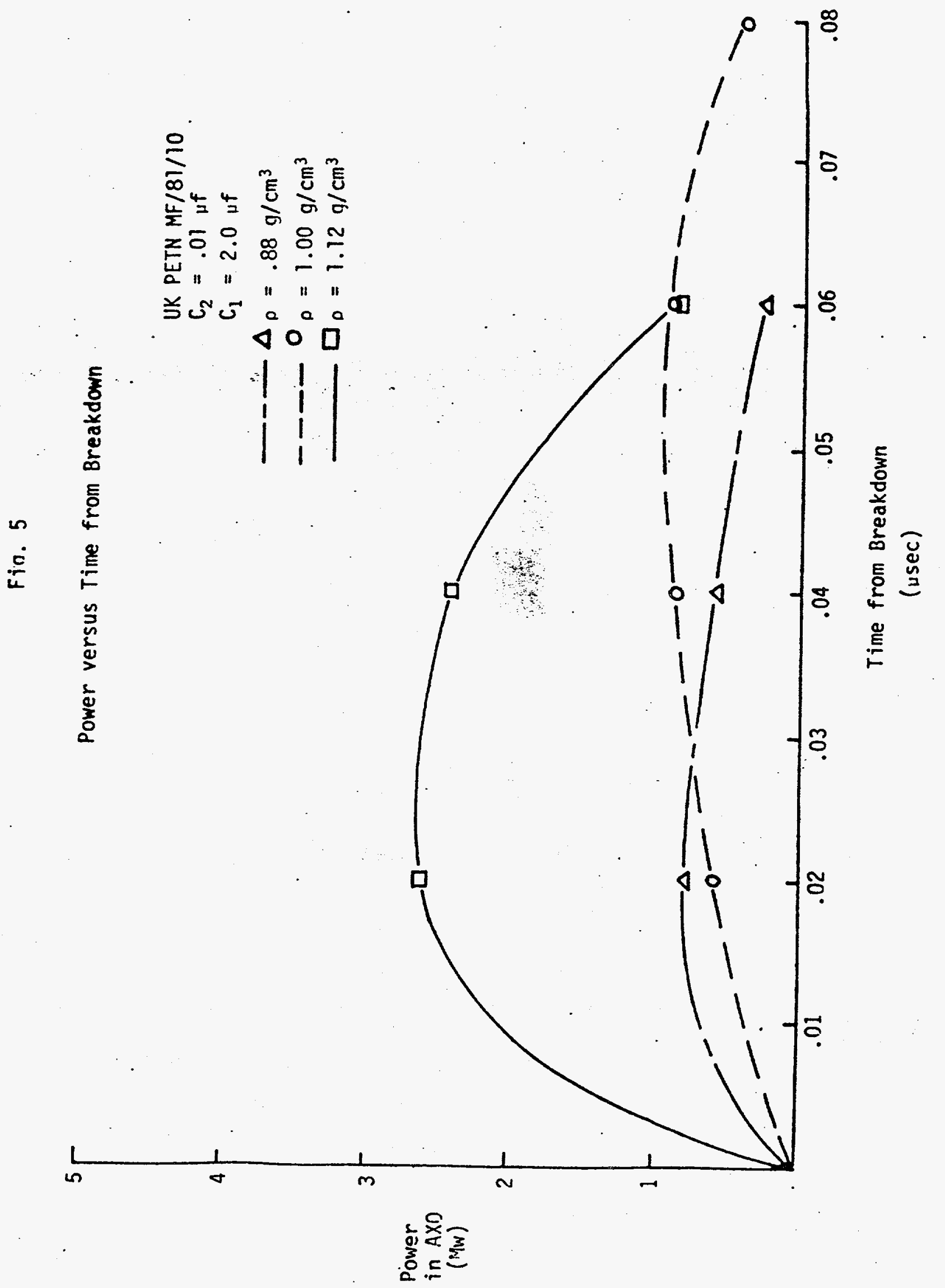




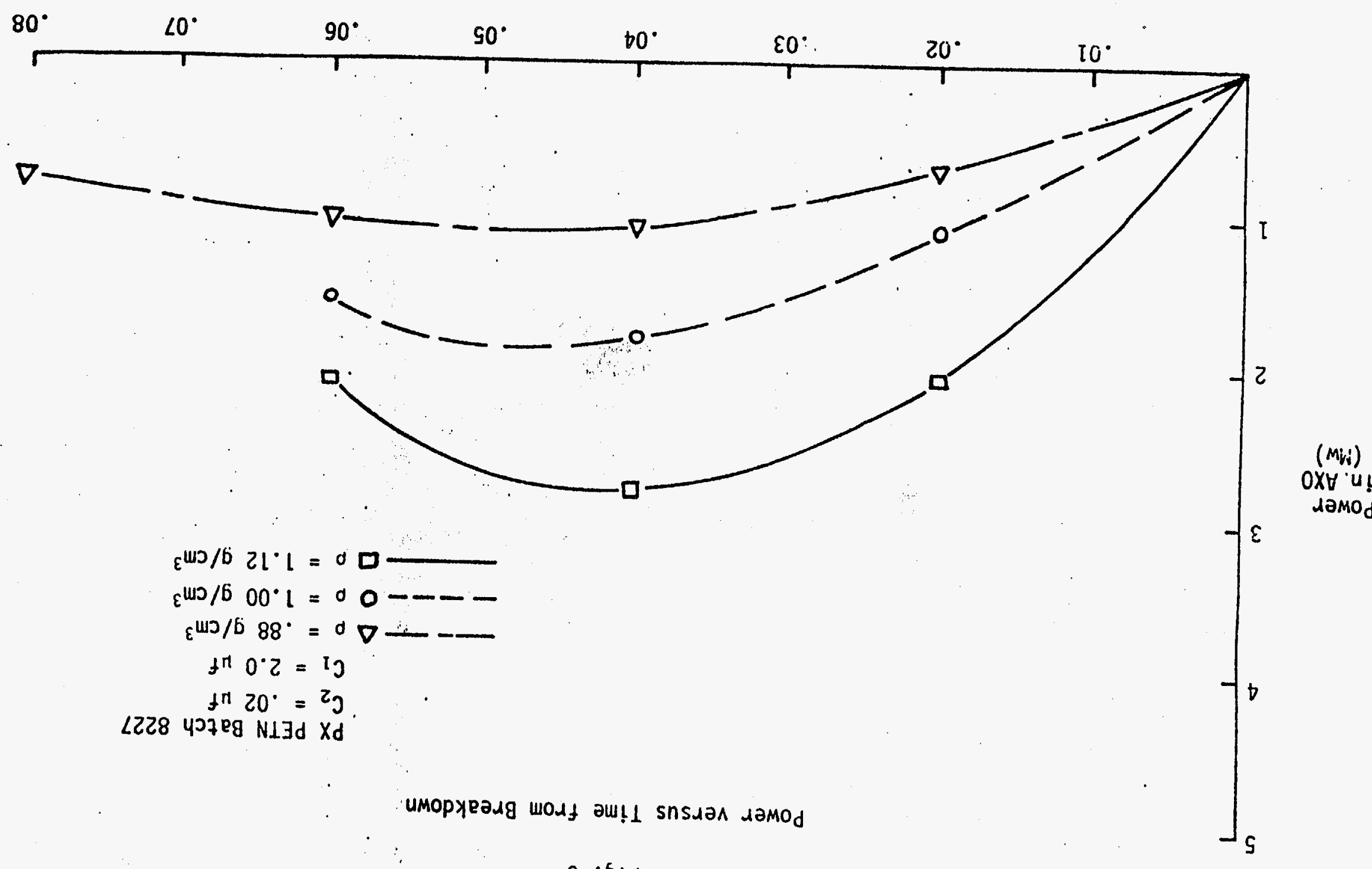

$$
9 \cdot 6 !\rfloor
$$



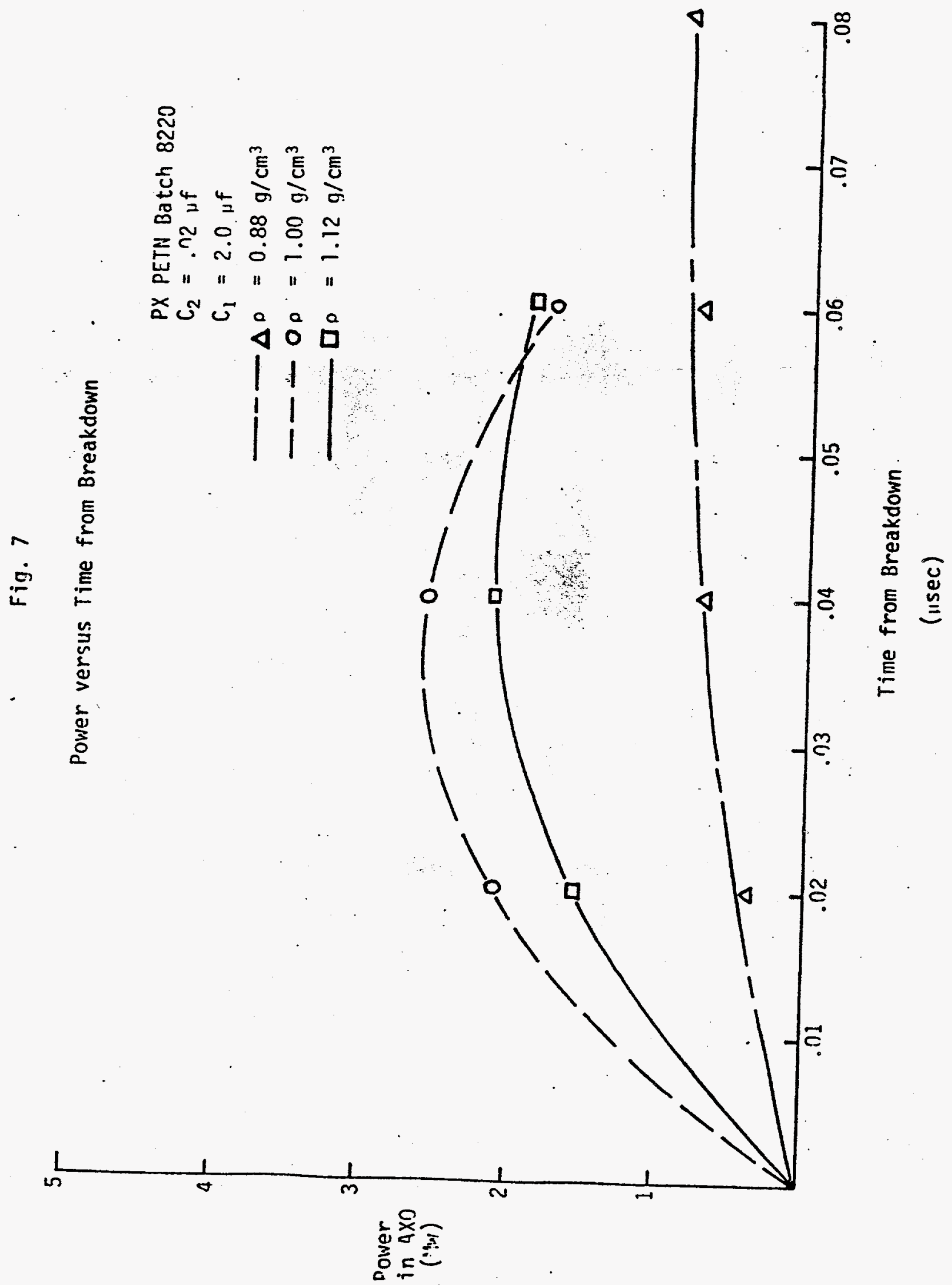
Fig. 8

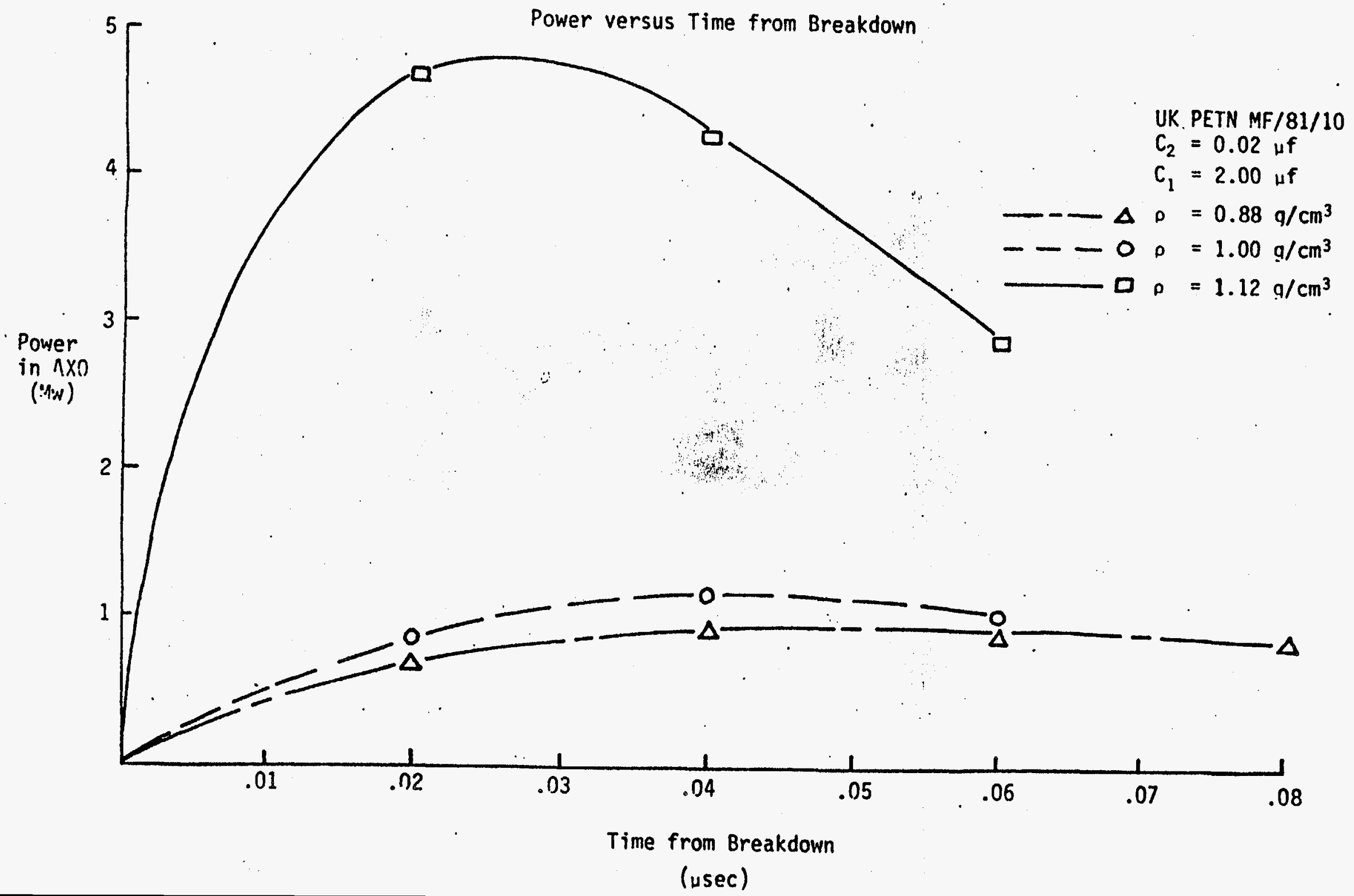


Fig. 9

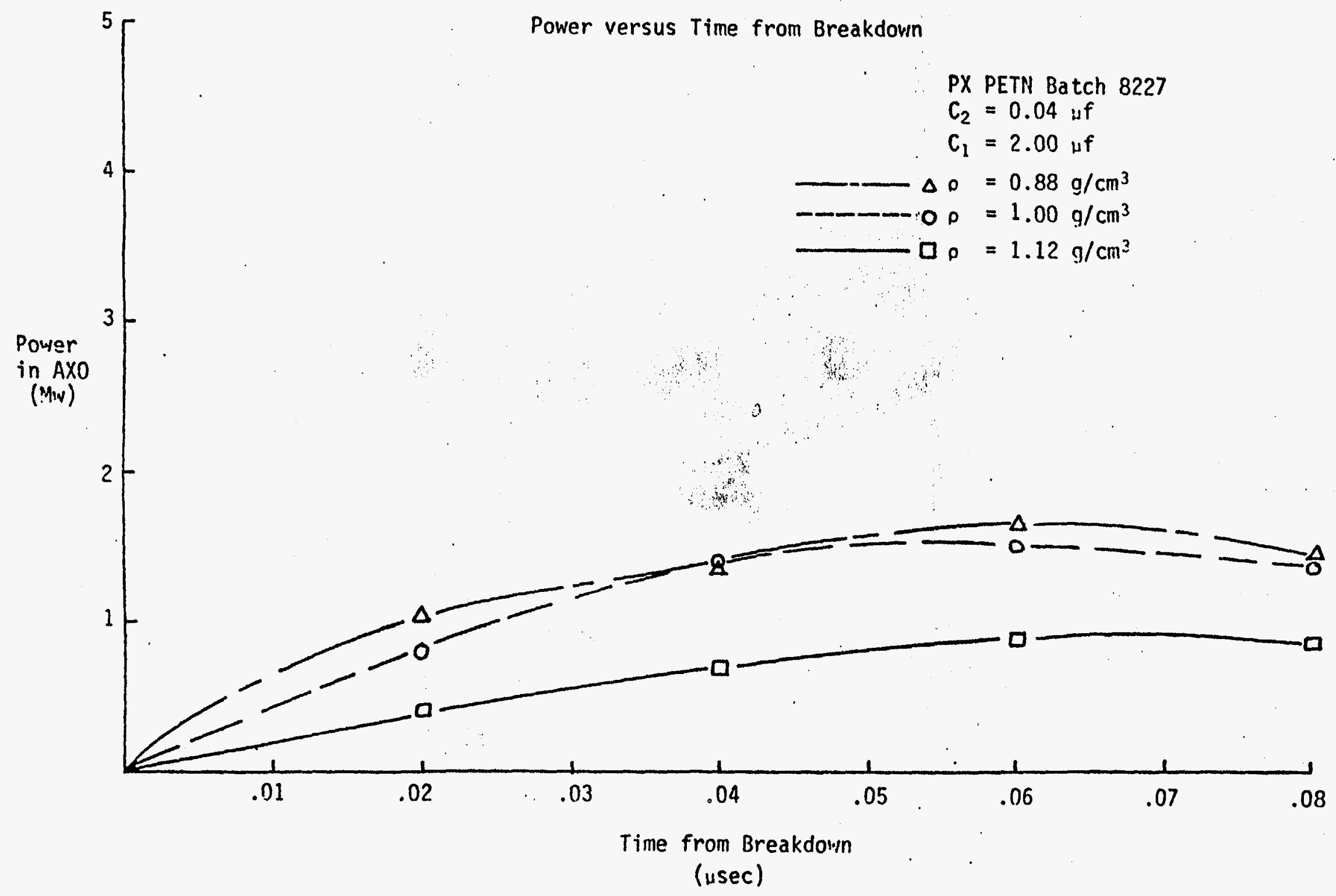


Fiọ. 10

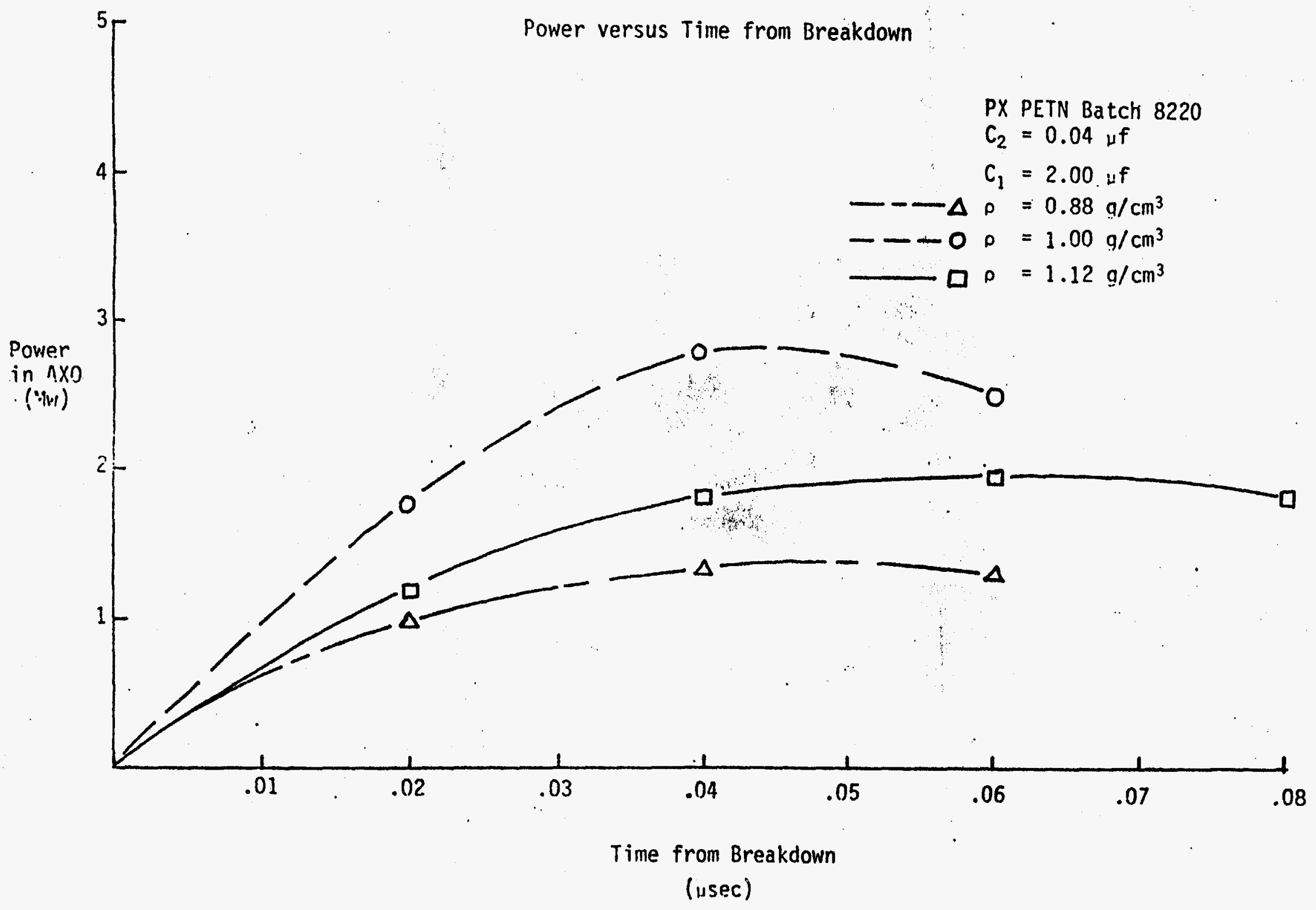




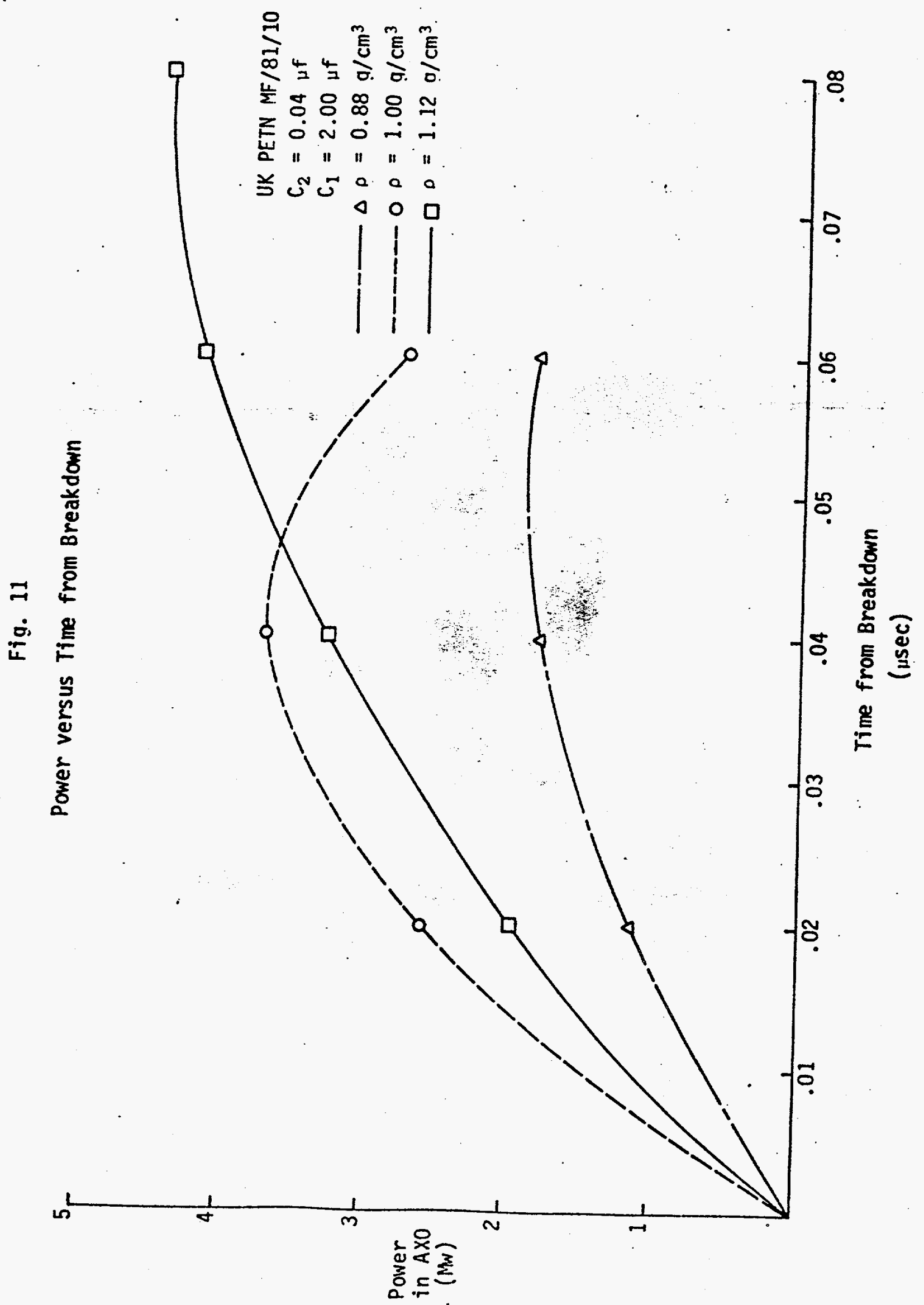


Table II

Analys is of Variance

Breakdown Vol tage (Kv)

Source of

Variation

Capacitance $\left(C_{2}\right)$

Specific Surface Area $\left(S_{0}^{P}\right)$

Density $(\rho)$

$C_{2} \times S_{0}^{P}$.

$C_{2} \times p$

$S_{0}^{P} \times \rho$

$C_{2} \times S_{0}^{p} \times \rho$

Total

Grand i'ean
Si'ms of

Squares

1822091

5952066

11174779

3079710

17666984

16349915

11650301

67695847

4640 \begin{tabular}{c} 
Degrees of \\
Freedom \\
\hline
\end{tabular}

2

2

2

4

4

4

8

26
Mean

Squar

9110

29760

55873

7699

441676

408747

145628

\section{Table III}

Analysis of Variance

Transmission Time ( $\mu \mathrm{sec}$ )

Source of

Variation

Capacitance $\left(C_{2}\right)$

Specific Surface Area $\left(S_{0}^{P}\right)$

Density (o)

$C_{2} \times S_{0}^{P}$

$C_{2} \times \rho$

$S_{0}^{P} \times \rho$

$C \times S_{0}^{P} \times \rho$

Total

Grand Mean
Sums of

Squares

0.09179

0.82801

0.00192

0.09259

0.12068

0.01393

0.04821

1.19712
Degrees of

Freedom:
Mean

Square:

0.0458 :

0.4140 r

0.0009 ;

0.0231

0.0301

0.0034

0.0060 .

8

26 
Table IV

Analys is of Variance

Peak Current (Amps)

\begin{tabular}{|c|c|c|}
\hline $\begin{array}{l}\text { Source of } \\
\text { Variation }\end{array}$ & $\begin{array}{l}\text { Sums of } \\
\text { Squares }\end{array}$ & $\begin{array}{l}\text { Degrees of } \\
\text { Freedom } \\
\end{array}$ \\
\hline Capacitance $\left(C_{2}\right)$ & 2181842 & 2 \\
\hline Specific Surface Area $\left(S_{0}^{P}\right)$ & 656021 & 2 \\
\hline Density $(0)$ & 666048 & 2 \\
\hline$C_{2} \times S_{0}^{P}$ & $376579^{\circ}$ & 4 \\
\hline$C_{2} \times \rho$ & 809659 & 4 \\
\hline$S_{0}^{P} \times p$ & 541740 & 4 \\
\hline$C_{2} \times S_{0}^{P} \times \rho$ & 317551 & 8 \\
\hline Total & 5549441 & 26 \\
\hline Grand Mean & & \\
\hline
\end{tabular}

Table V

Analysis of Variance

Peak Power (kw)

Source of

Variation

Capacitance $\left(C_{2}\right)$

Specific Surface Area $\left(S_{0}^{P}\right)$

Density ( $p$ )

$c_{2} \times S_{0}^{P}$

$\mathrm{C}_{2} \times \rho$

$5_{0}^{P} \times \rho$

$C_{2} \times S_{0}^{P} \times$

Total

Grand Mean \begin{tabular}{ll} 
Sums of & $\begin{array}{c}\text { Degrees of } \\
\text { Freedom }\end{array}$ \\
\hline
\end{tabular}

3519789

3053826

5862466

2599227

4179889

5939566

2483699

27638462
Mean

Squares

1090921

328011

333024

94145

202415

135435

39694 
Table VI

Analysis of Variance

di/dt Breakdown (Amps/usec)

Source of

Variation

Capacitance $\left(C_{2}\right)$

Specific Surface Area $\left(S_{0}^{P}\right)$

Density ( 0 )

$C_{2} \times S_{0}^{P}$

$C_{2} \times p$

$S_{0}^{P} \times \rho$

$C_{2} \times s_{0}^{P} \times 0$

Total

Grand Mean

18200
Sums of

Squares

6235642

3201606

55239948

237750212

101211025

13538623

314232893

731409949
Degrees of Freedom

2

2

2

4

4

4.

8

26
Mean

Squares

3117821

1600803

27619974

59437553

25302756

3384656

39279112

Table VII

Analys is of Variance

$\mathrm{dv} / \mathrm{dt}$ of Voltage Ramp ( $\mathrm{v} / \mathrm{usec}$ )

Source of

Variation

Capacitance $\left(C_{2}\right)$

Specific Surface Area $\left(S_{0}^{P}\right)$

Density $(0)$

$C_{2} \times S_{0}^{P}$

$C_{2} \times \rho$

$S_{0}^{P} \times p$

$\mathrm{C}_{2} \times \mathrm{S}_{0}^{\mathrm{P}} \times \rho$

Total

Grand Mean

\begin{tabular}{ll}
$\begin{array}{l}\text { Sums of } \\
\text { Squares }\end{array}$ & $\begin{array}{l}\text { Degrees of } \\
\text { Freedom }\end{array}$ \\
\hline
\end{tabular}

1146937177

53274184

99561529

87019032

296755728

59251807

192860786

1935460240
2

2

2

4

4

4

8

26
Mean

Squares

573468588

26632091

49930765

21754758

74188932

14812952

24107595 
$\frac{9}{5}$

Fig. 12

9

Breakdown Voltage versus Density

(Vertical bands are plus and minus $\sigma$ )

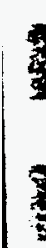

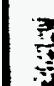

7

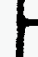

害

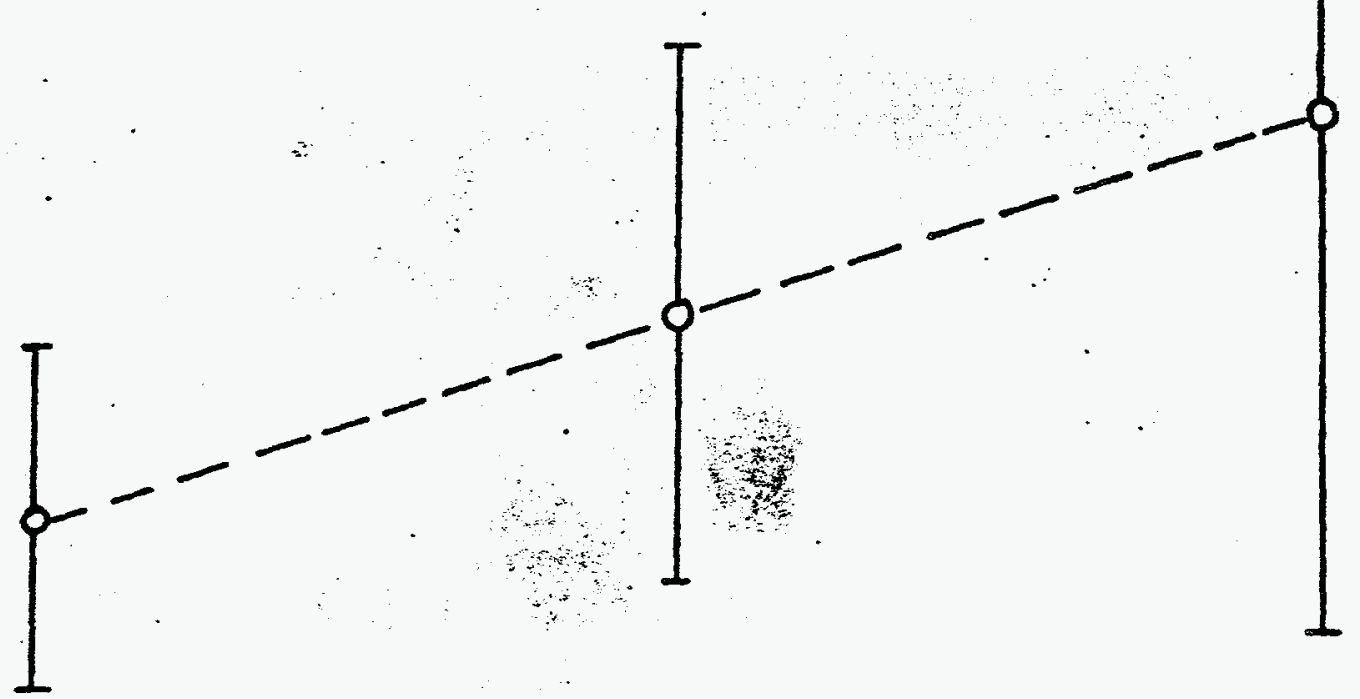

1

3

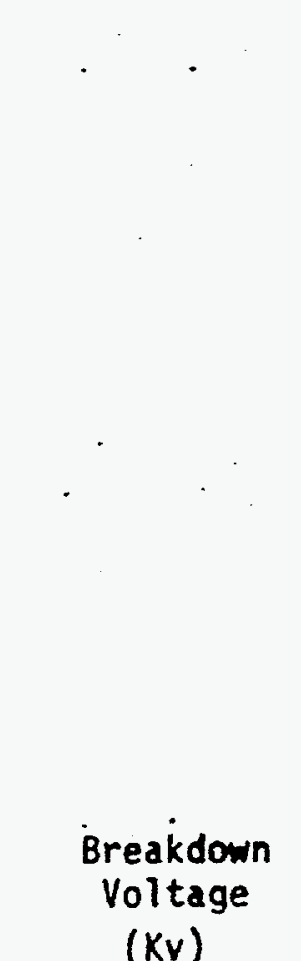

7

5

4

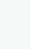


19.13

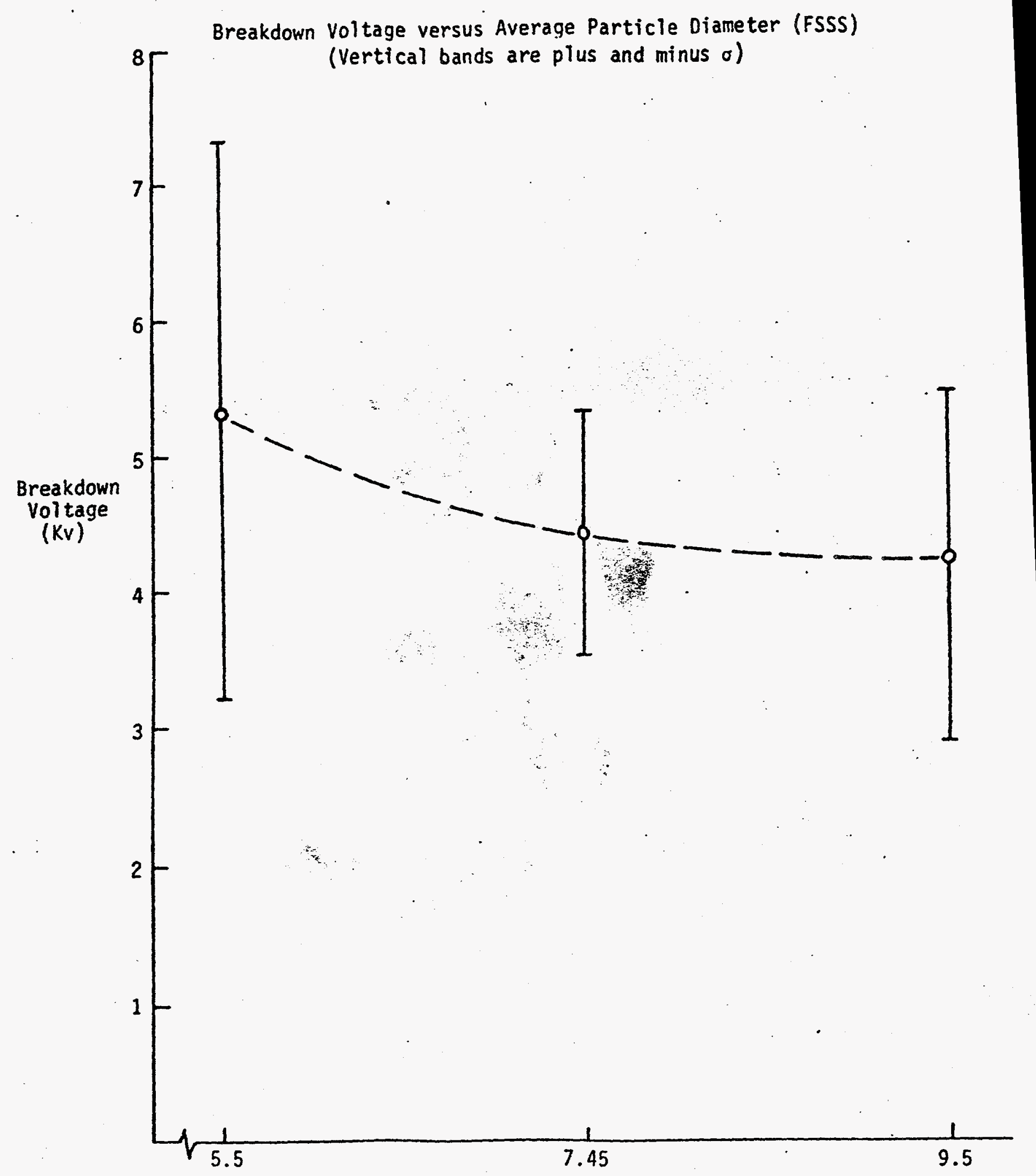

Average Particle Diameter

(Microns) 
Fig. 14

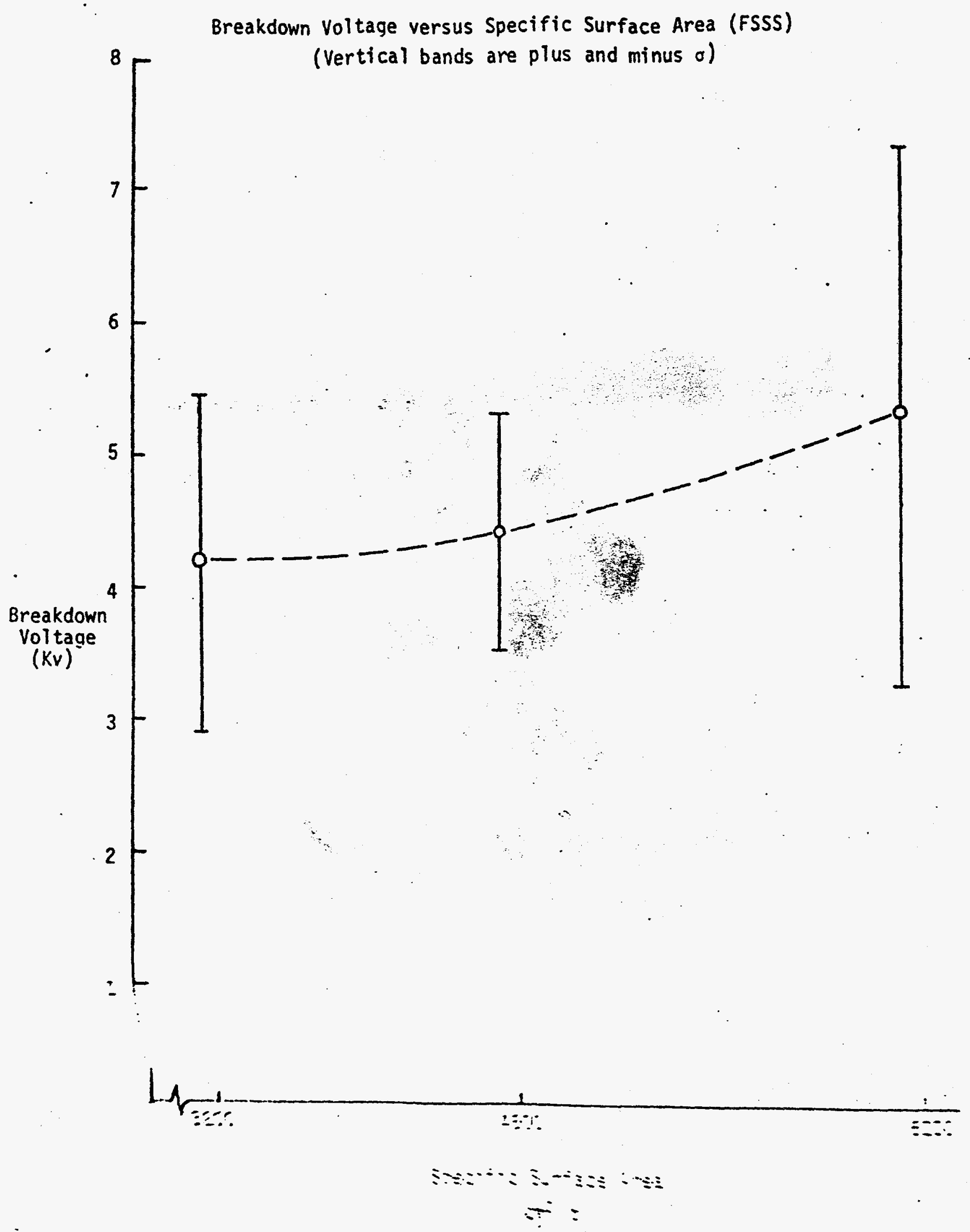


Fig. 15

Breakdown Voltage versus Density

(Vertical bands are plus and minus $\sigma$ )

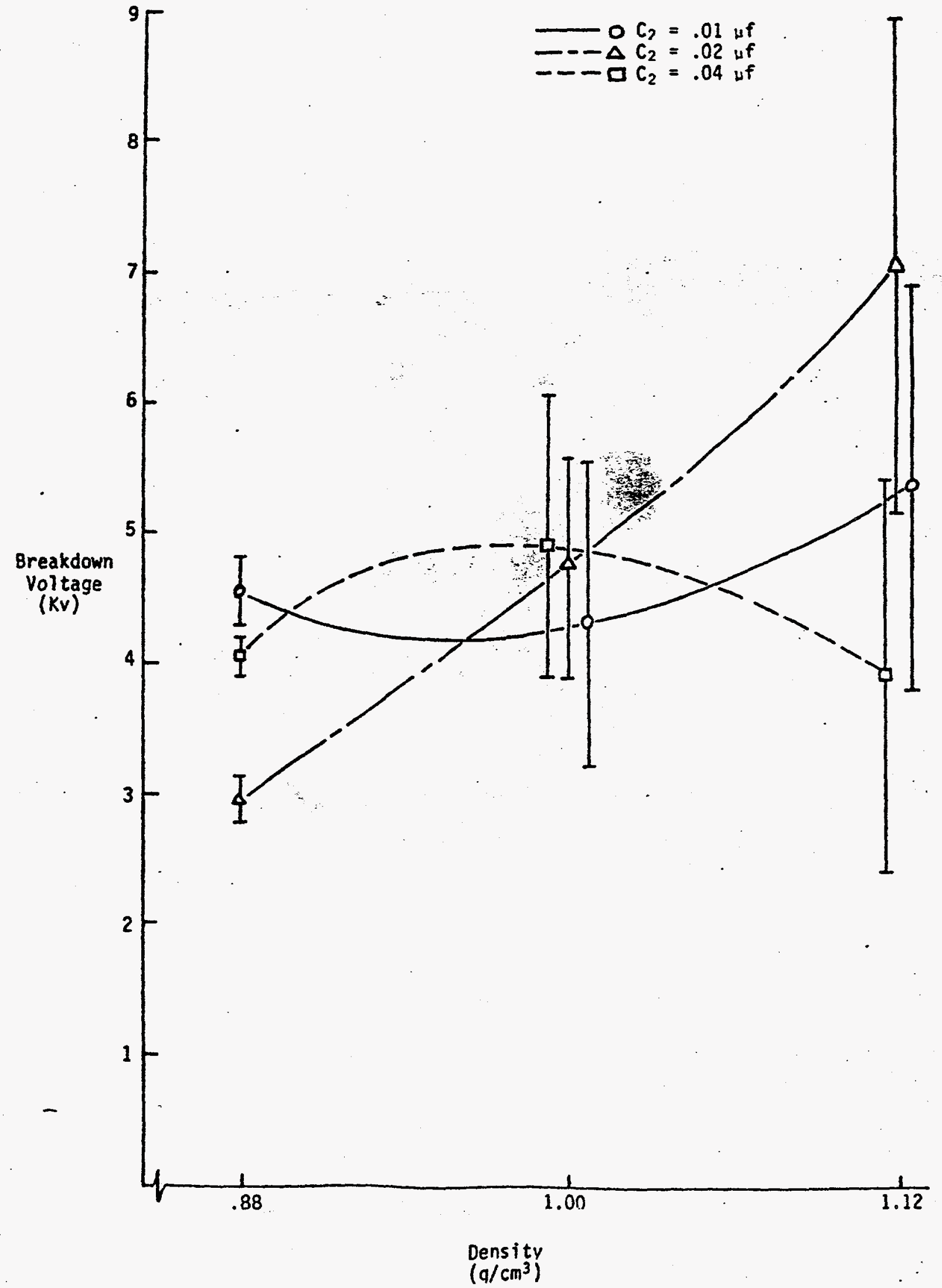


Fig. 16

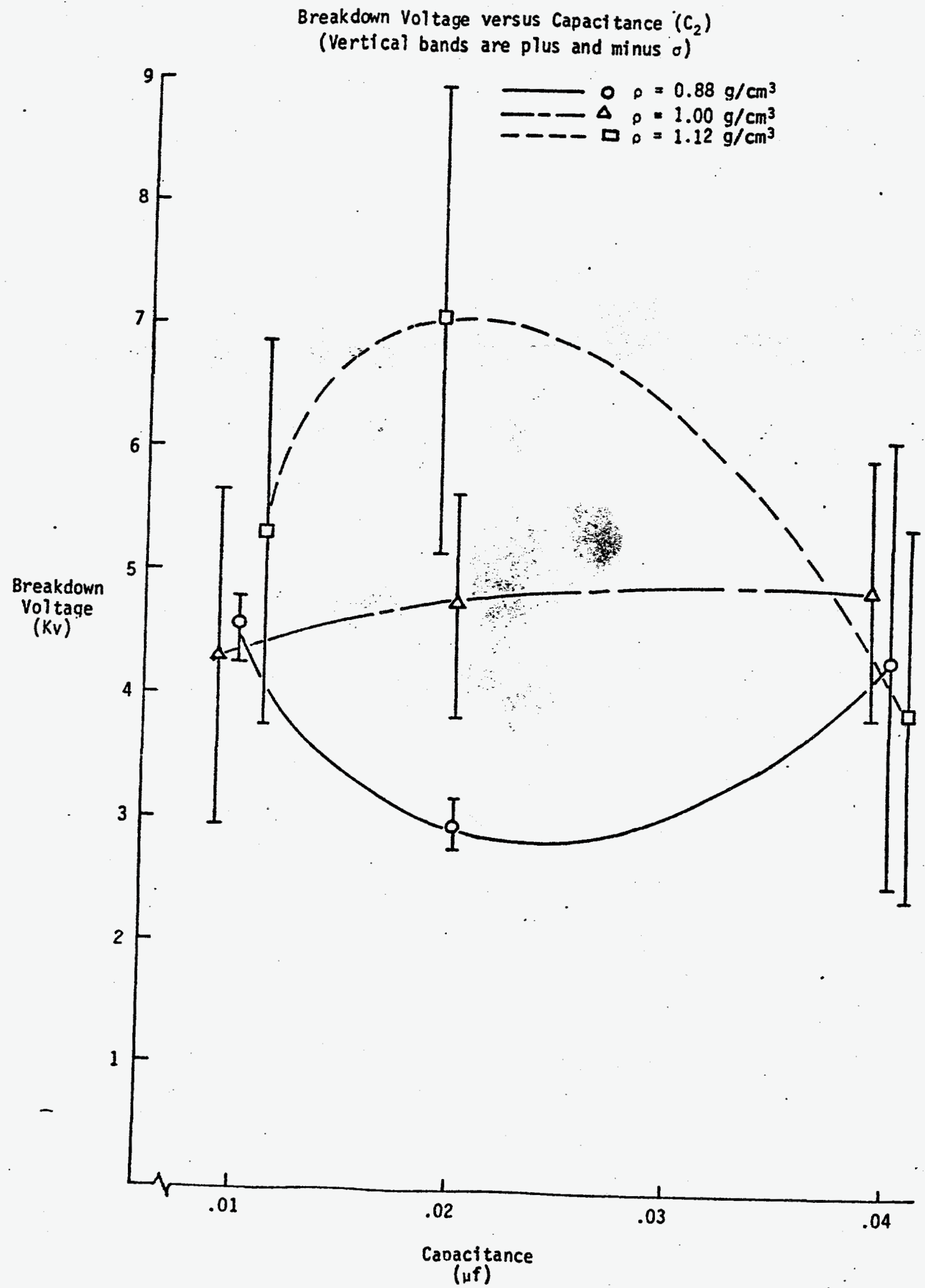


Fig. 17

Breakdown Voltage versus Density

(Vertical bands are plus and minus o)

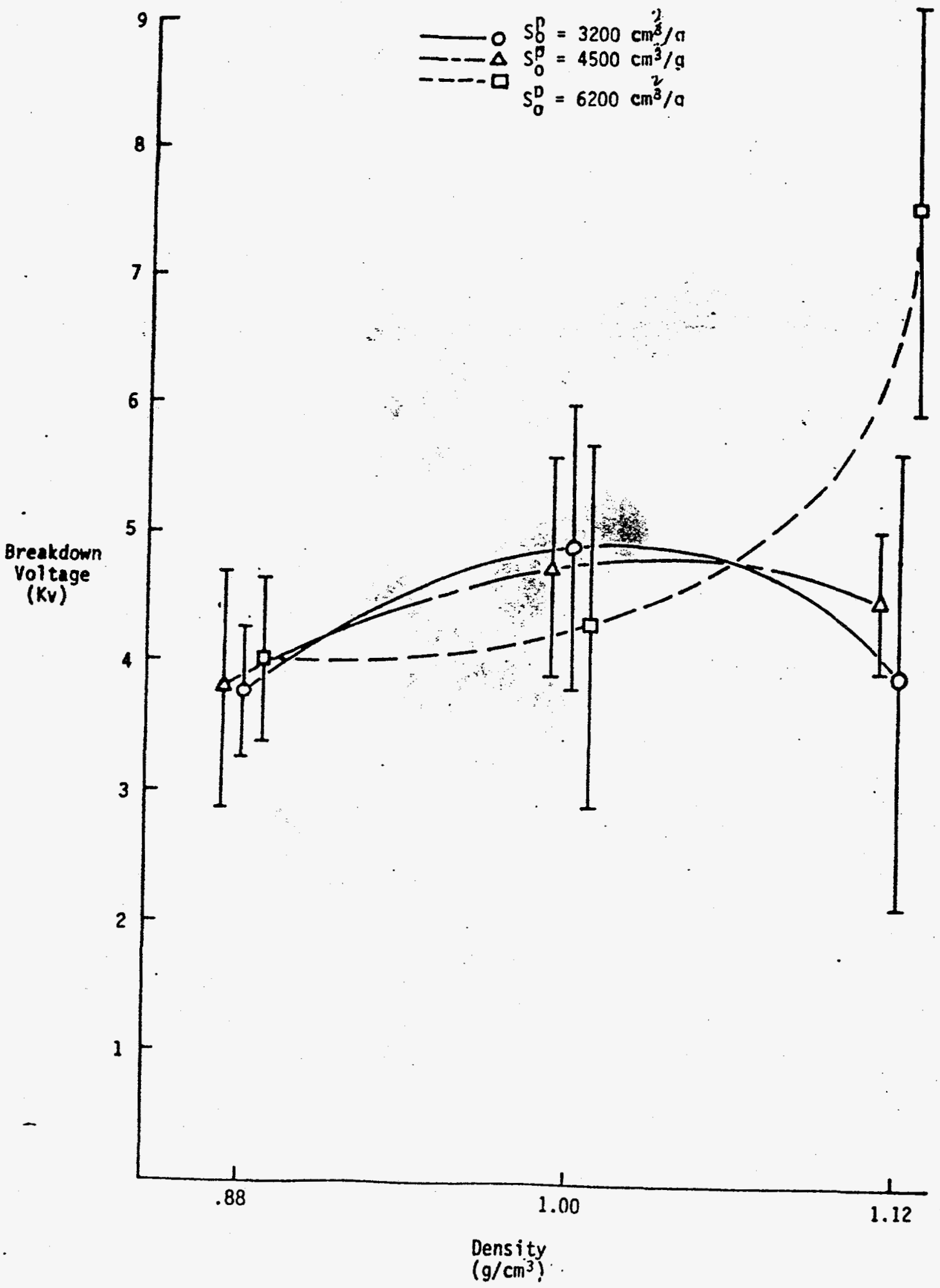


Fig. 18

Breakdown Voltage versus Average Particle Diameter (FSSS)

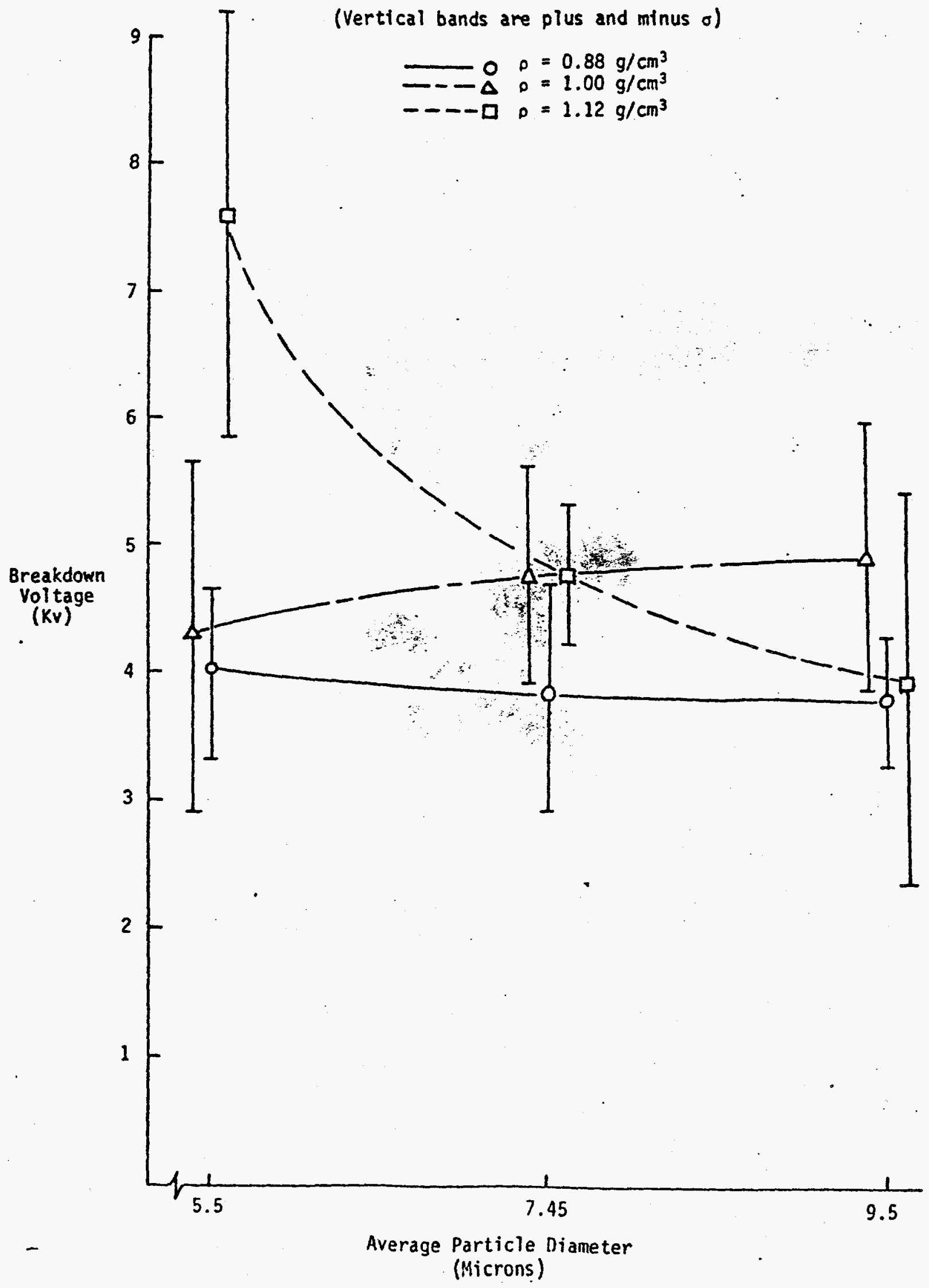




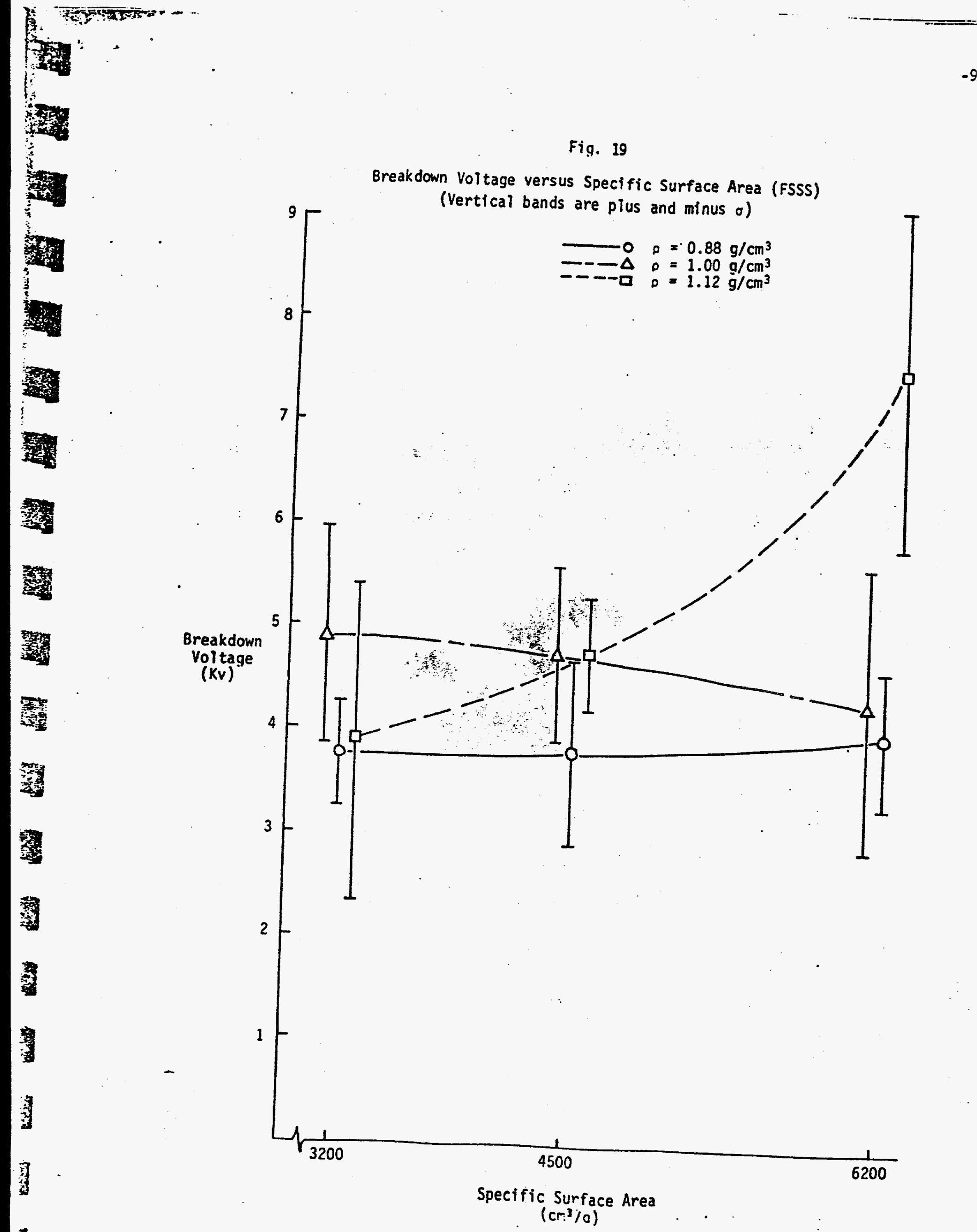


1

Fig. 20

1

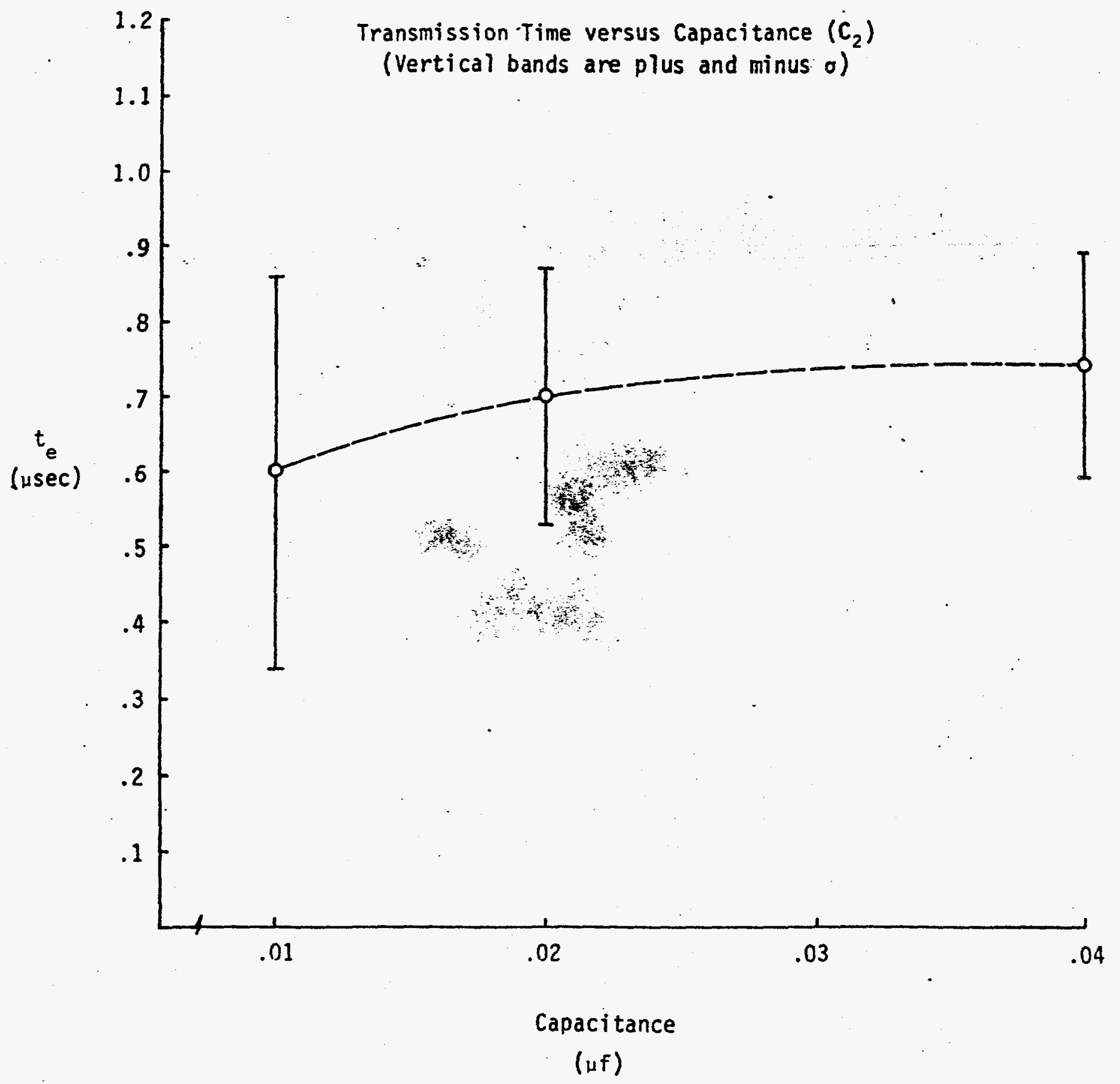


Fig. 21

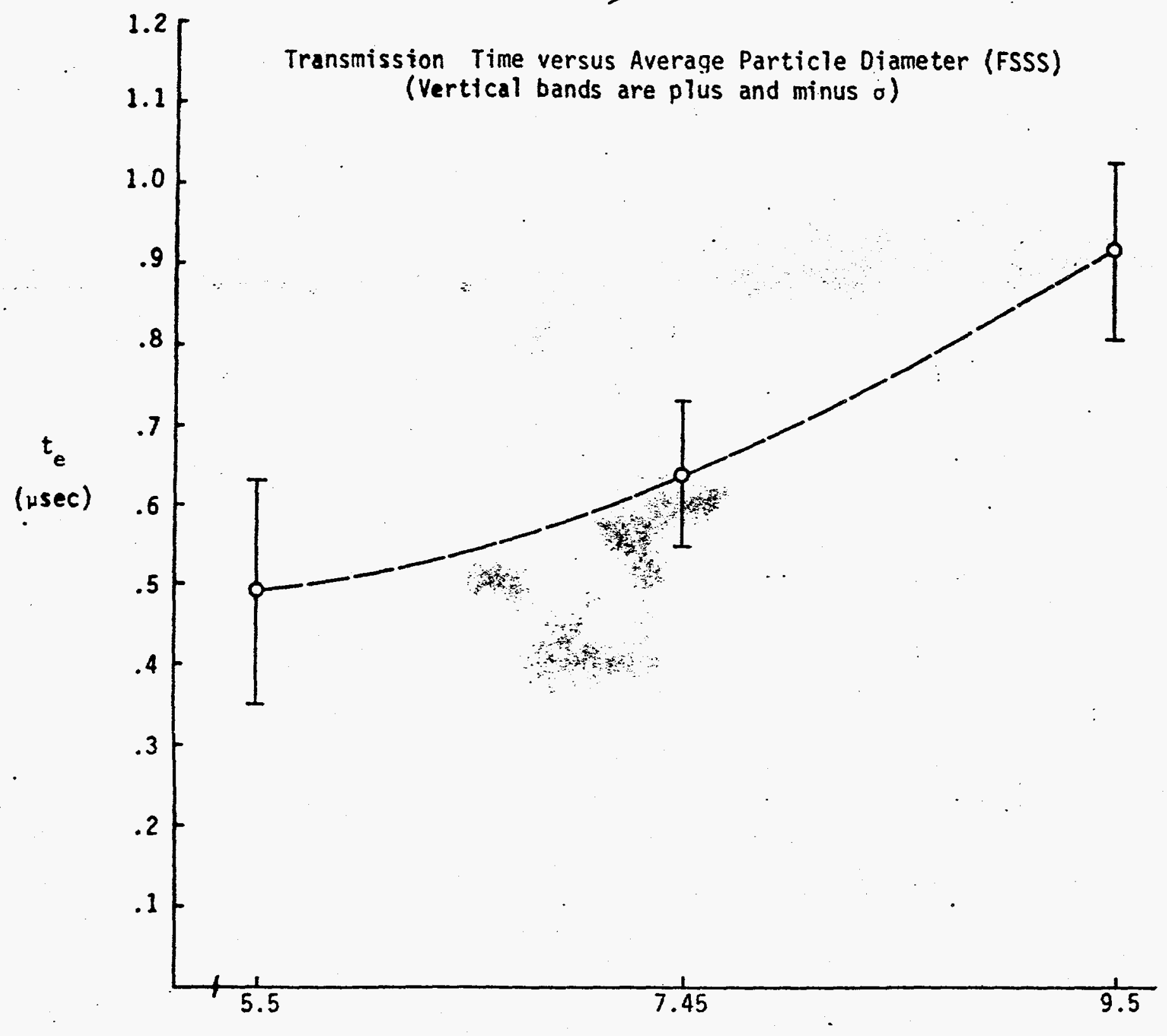

Average Particle Diameter

(Microns) 
Fig. 22

Transmission Time versus Specific Surface Area

(FSSS)

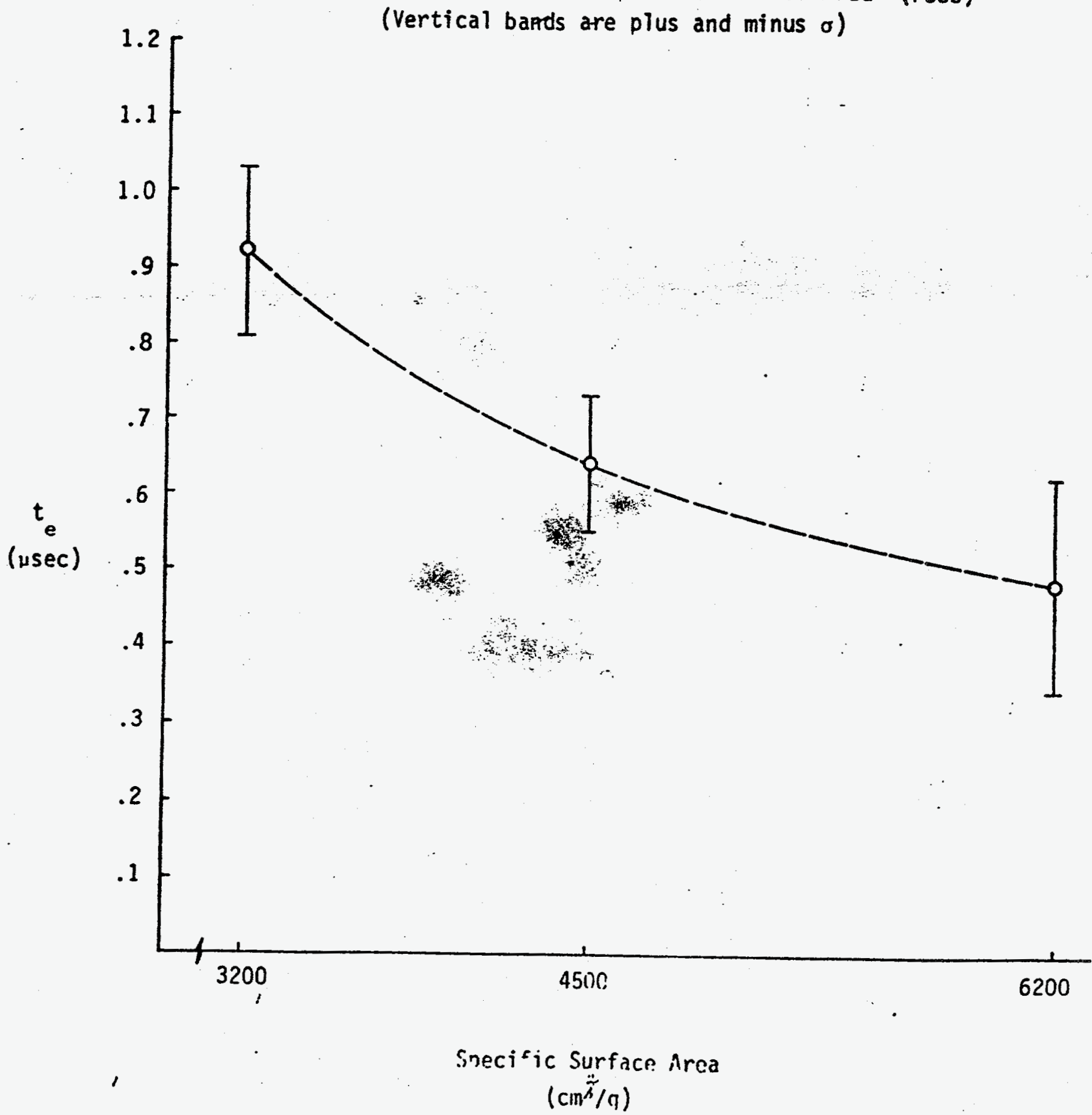



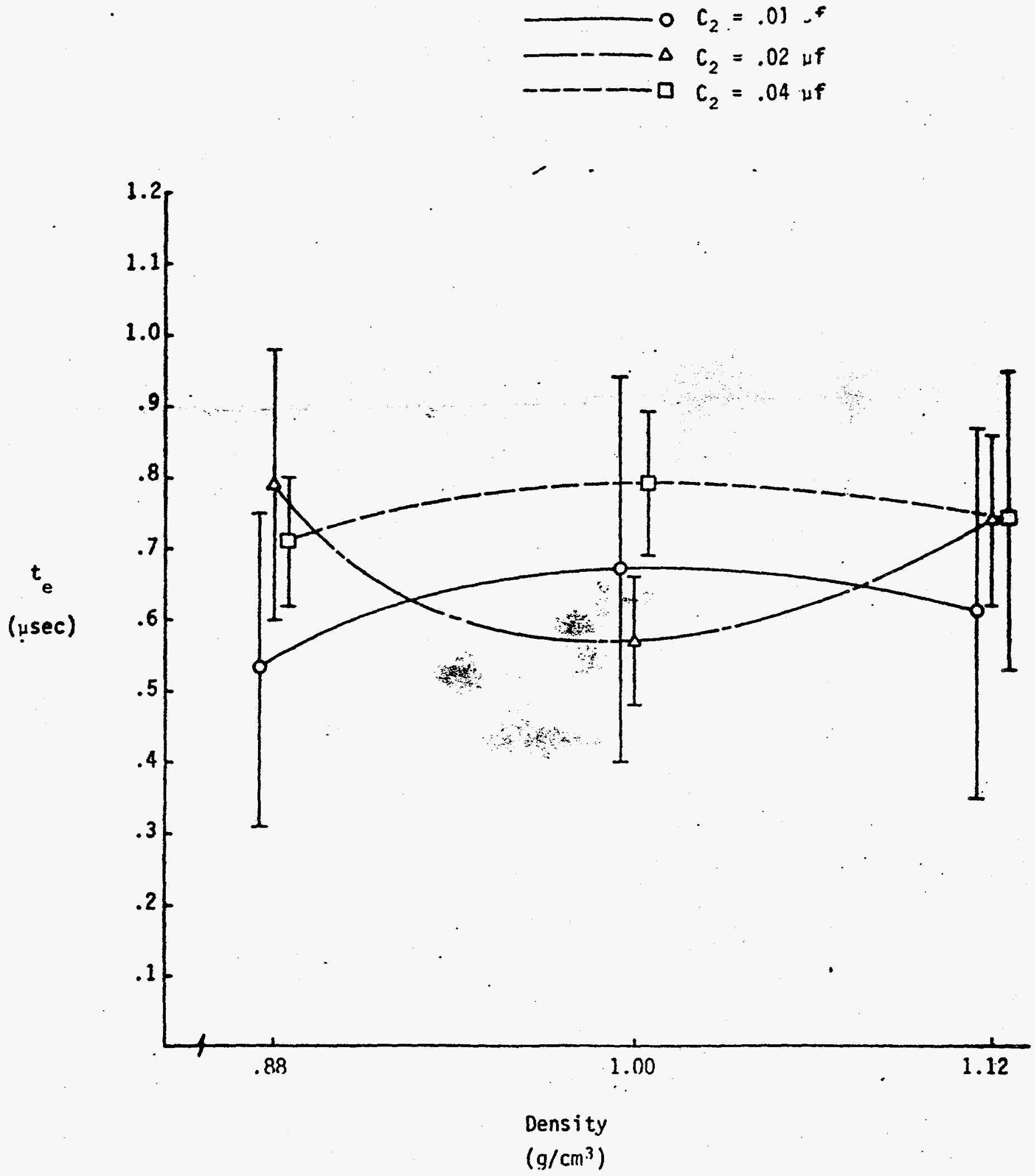

Transmission Time versus Density

(Vertical bands are plus and minus $\sigma$ )

Fig. 23 

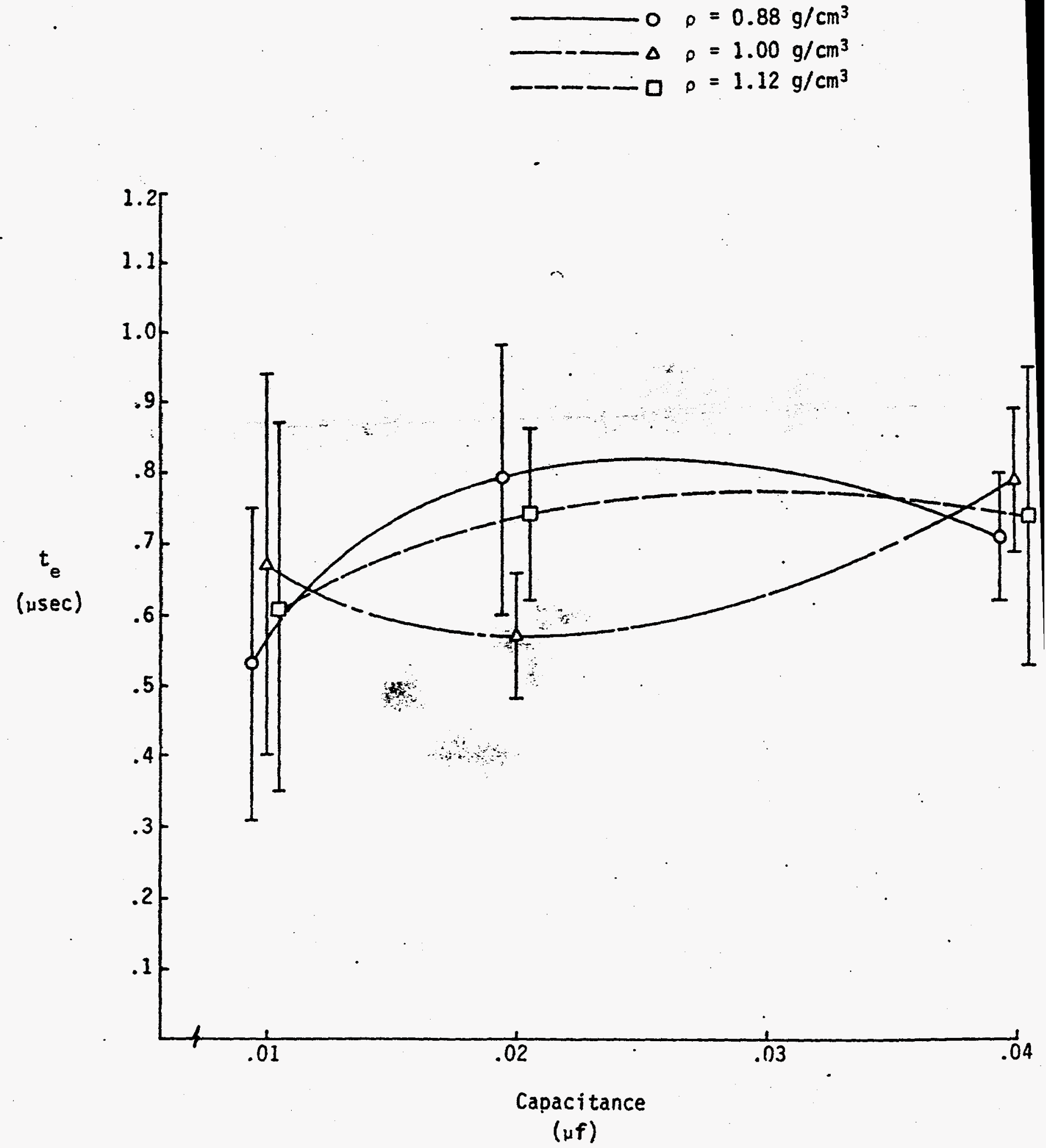

Transmission Time versus Capacitance $\left(C_{2}\right)$

(Vertical bands are plus and minus o)

Fig. 24 
3

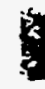

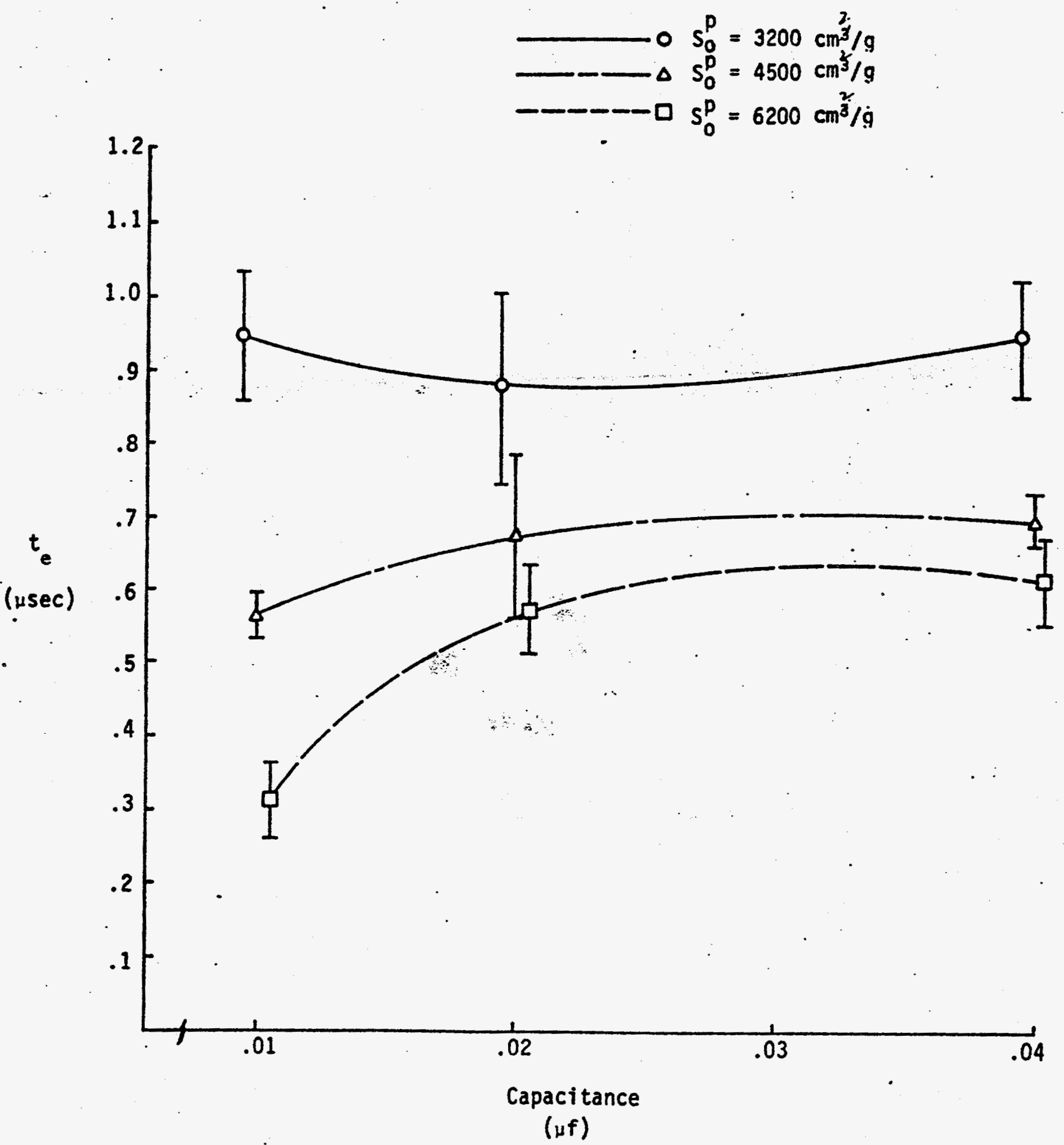

Transmission Time versus Capacitance $\left(C_{2}\right)$

(Vertical bands are plus and minus $\sigma$ )

Fig. 25 


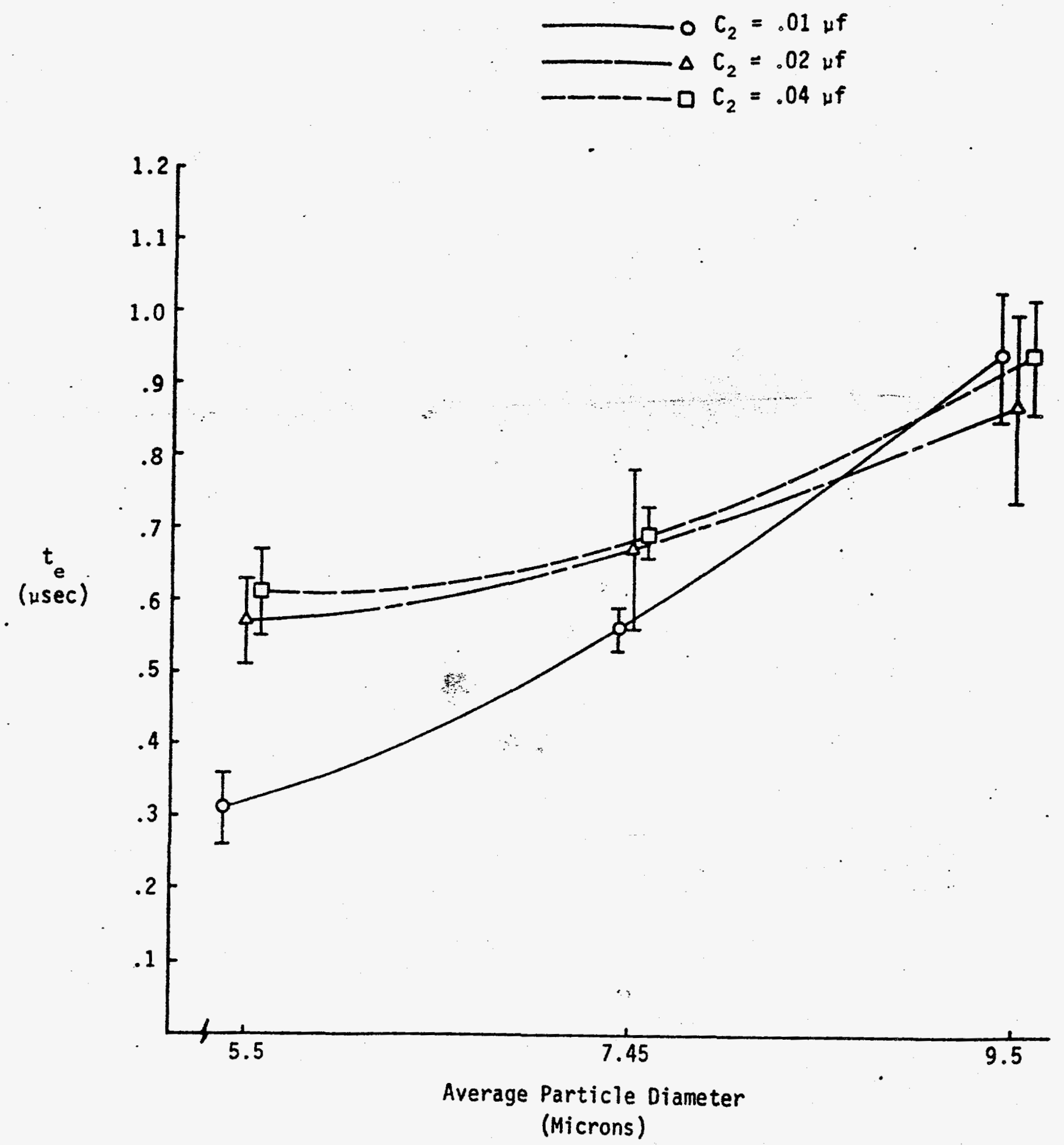

Transmission Time versus Average Particle Diameter. (FSSS)

(Vertical bands are plus and minus o)

Fia. 26 


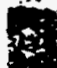
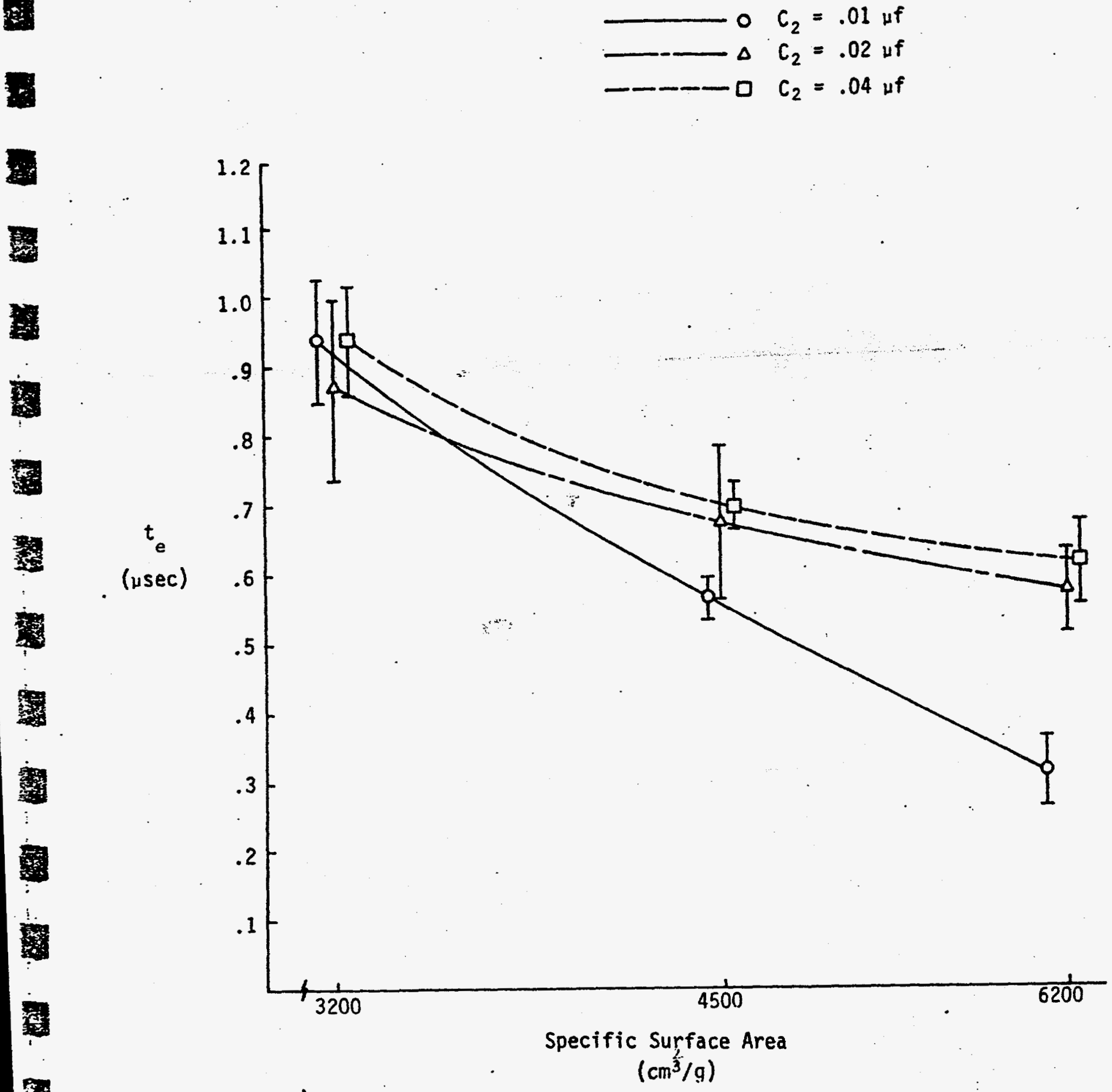

Transmission Time versus Specific Surface Area (FSSS)

(Vertical bands are plus and minus of

Fig. 27 


\section{FUTURE WORK; COMMENTS; CONCLUSIONS}

Some qualitative conclusions may be drawn from visual inspection of the plots as to the relative effects of each parameter.

As might be expected the breakdown voltage exhibits significant dependence upon $\rho$, and possible $S_{0}^{P}$. In addition the interaction of owith $S_{0}^{P}$ appears to affect the breakdown voltage.

In all tests performed UK PETN at $1.12 \mathrm{~g} / \mathrm{cm}^{3}$ showed high dielectric strength (high $V_{B D}$ ). The main-effect plot of the action of density on $V_{B D}$ gives an indication of the packing properties of each powder type since $V_{B D}$ is related to the arc path length and shape through the powder.

The power curves for the high density UK PETN illustrate the enormous power which can be delivered to the AXO detonator. Note that the power curve may maximize at a different density for each batch although the overall trend is to maximize at the higher density.

Transmission time, $t_{e}$, shows an inverse dependence upon $S_{0}^{P}$ (thus a direct dependence on average particle diameter). This is the most clearly observed effect in the experiment. But $t_{e}$ shows no dependence upon density within the limits tested. This result may be due to canceling effects of induction time versus detonation velocity.

Shorter $t_{e}$ at lower $C_{2}$ values are attributable to the higher di/dt attained. UK PETN proved to be unique among the three powders tested; its properties appear to be quite different from those of PX PETN in the AXO configurations. Thus, in 
some ways (e.g., direct comparison of those levels of $S_{0}^{P}$ ) its choice was not rigorously optimum for this experiment; but the unexpected difference information outweighs the loss of rigor in the third level of $S_{0}^{P}$.

A method to measure the time of ignition should be developed in order to obtain more useful information about the amount of input energy actually expended in the detonation process. Cutback studies should be performed to ascertain the minimum $H E$ thickness required for detonation.

Some of the other spark gap detonator factors which require investigation are potential hazards in the field or other safety aspects, environmental effects, and specific applications.

\title{
DISCLAIMER
}

\begin{abstract}
This report was prepared as an account of work sponsored by an agency of the United States Government. Neither the United States Government nor any agency thereof, nor any of their employees, makes any warranty, express or implied, or assumes any legal liability or responsibility for the accuracy, completeness, or usefulness of any information, apparatus, product, or process disclosed, or represents that its use would not infringe privately owned rights. Reference herein to any specific commercial product, process, or service by trade name, trademark, manufacturer, or otherwise does not necessarily constitute or imply its endorsement, recommendation, or favoring by the United States Government or any agency thereof. The views and opinions of authors expressed herein do not necessarily state or reflect those of the United States Government or any agency thereof.
\end{abstract}




\section{DISCLAIMIER}

Portions of this document may be illegible in electronic image products. Insages are produced from the best available originsl document. 